Check for updates

Cite this: Metallomics, 2020, 12, 1995

Received 1st July 2020,

Accepted 27th October 2020

DOI: $10.1039 / \mathrm{d} 0 \mathrm{mt} 00156 \mathrm{~b}$

rsc.li/metallomics

\section{Altered copper homeostasis underlies sensitivity of hepatocellular carcinoma to copper chelation}

\author{
Caroline I. Davis, (D) ${ }^{a}$ Xingxing Gu, ${ }^{b}$ Ryan M. Kiefer, ${ }^{\text {cd }}$ Martina Ralle, (D) e \\ Terence P. Gade ${ }^{\text {bdfg }}$ and Donita C. Brady (D)*bf
}

\begin{abstract}
Hepatocellular carcinoma (HCC), the most common primary liver cancer, of which $~ 800000$ new cases will be diagnosed worldwide this year, portends a five-year survival rate of merely $17 \%$ in patients with unresectable disease. This dismal prognosis is due, at least in part, from the late stage of diagnosis and the limited efficacy of systemic therapies. As a result, there is an urgent need to identify risk factors that contribute to HCC initiation and provide targetable vulnerabilities to improve patient survival. While myriad risk factors are known, elevated copper $(\mathrm{Cu})$ levels in HCC patients and the incidence of hepatobiliary malignancies in Wilson disease patients, which exhibit hereditary liver $\mathrm{Cu}$ overload, suggests the possibility that metal accumulation promotes malignant transformation. Here we found that expression of the Cu transporter genes ATP7A, ATP7B, SLC31A1, and SLC31A2 was significantly altered in liver cancer samples and were associated with elevated $\mathrm{Cu}$ levels in liver cancer tissue and cells. Further analysis of genomic copy number data revealed that alterations in $\mathrm{Cu}$ transporter gene loci correlate with poorer survival in HCC patients. Genetic loss of the Cu importer SLC31A1 (CTR1) or pharmacologic suppression of $\mathrm{Cu}$ decreased the viability, clonogenic survival, and anchorage-independent growth of human HCC cell lines. Mechanistically, CTR1 knockdown or $\mathrm{Cu}$ chelation decreased glycolytic gene expression and downstream metabolite utilization and as a result forestalled tumor cell survival after exposure to hypoxia, which mimics oxygen deprivation elicited by transarterial embolization, a standard-of-care therapy used for patients with unresectable HCC. Taken together, these findings established an association between altered $\mathrm{Cu}$ homeostasis and $\mathrm{HCC}$ and suggest that limiting $\mathrm{Cu}$ bioavailability may provide a new treatment strategy for HCC by restricting the metabolic reprogramming necessary for cancer cell survival.
\end{abstract}

Significance to metallomics

HCC represents an alarming global healthcare problem with an increasing incidence. Current treatment strategies for HCC demonstrate limited efficacy because each is agnostic to molecular and genetic features of the disease. Although significant elevation of the transition metal Cu has been associated with HCC, the contribution of $\mathrm{Cu}$ to hepatocarcinogenesis is not well understood. Here, we present an analysis of altered Cu transporter expression in HCC that elucidated a unique Cu-dependent vulnerability within glycolytic metabolism necessary for tumorigenesis. These findings uncover a clinically tractable alternative treatment to combat HCC by repurposing Cu chelators.

${ }^{a}$ Biochemistry and Molecular Biophysics Graduate Group, Perelman School of Medicine, University of Pennsylvania, Philadelphia, PA, 19104, USA

${ }^{b}$ Department of Cancer Biology, Perelman School of Medicine, University of Pennsylvania, Philadelphia, PA, 19104, USA. E-mail: bradyd@pennmedicine.upenn.edu

${ }^{c}$ Medical Degree Program, Perelman School of Medicine, University of Pennsylvania, Philadelphia, PA, 19104, USA

${ }^{d}$ Penn Image-Guided Interventions Laboratory, Perelman School of Medicine, University of Pennsylvania, Philadelphia, PA, 19104, USA

${ }^{e}$ Department of Molecular and Medical Genetics, Oregon Health and Science University, Portland, OR, 97239, USA

${ }^{f}$ Abramson Family Cancer Research Institute, Perelman School of Medicine, University of Pennsylvania, Philadelphia, PA, 19104, USA

${ }^{g}$ Department of Radiology, Perelman School of Medicine,

University of Pennsylvania, Philadelphia, PA 19104, USA

\section{Introduction}

Liver cancer represents the second and the sixth leading cause of cancer-related death in men and women, respectively. ${ }^{1}$ HCC accounts for $80 \%$ of liver cancer cases in the world, ${ }^{2}$ and preexisting conditions associated with cirrhosis, such as hepatitis B viral infection, chronic hepatitis $\mathrm{C}$ virus infection, nonalcoholic fatty liver disease, hereditary hemochromatosis, and Wilson disease contribute to HCC onset. ${ }^{3}$ Genomic alterations within HCC, irrespective of etiologic risk factor, emphasize the heterogeneous nature of the disease and thus, advances in molecular medicine targeting the genetic mutations underlying 
HCC have been unsuccessful. ${ }^{4}$ Like most cancers, surgical therapies (resection and liver transplantation) and locoregional procedures (radiofrequency ablation) are an effective first line of treatment for localized HCC, with five-year survival rates of up to 60 to $70 \% .^{5}$ Unfortunately, the majority of HCC cases are diagnosed at late stage with only $20 \%$ of patients meeting criteria for curative intervention, and the treatment options for intermediate and advanced disease are limited. ${ }^{6}$ Specifically for intermediate or advanced stage HCC, locoregional therapies including, transarterial embolization (TAE) and transarterial chemoembolization (TACE), ${ }^{5}$ which take advantage of obstructing tumor blood supply with or without local chemotherapy, or systemic therapy with sorafenib, ${ }^{7,8}$ a small molecule multikinase inhibitor, provide limited survival benefits. Although obstruction of tumor blood flow limits the delivery of oxygen and nutrients to promote cancer cell death, surviving cells contribute to recurrent HCC following TAE or TACE. ${ }^{6,9-11}$ The local hypoxic environment induced by TAE and TACE stabilizes the oxygen sensitive master transcription factor, hypoxia inducible factor 1 (HIF-1), which upregulates numerous genes in pro-survival pathways, including glycolysis, essential for cancer cell adaptation. ${ }^{12}$ Thus, there is a great need to discover unique cellular and molecular features of HCC that can be exploited as novel approaches to treat advanced disease and limit resistance.

Case studies of patients with Wilson Disease, which harbor germline mutations in the gene encoding the P-type ATPase $A T P 7 B,{ }^{13,14}$ demonstrate that persistently elevated levels of intracellular $\mathrm{Cu}$ impair liver function such that HCC results as a complication. ${ }^{15-18}$ Beyond the extensive research from both Wilson disease patients and animals that supports a connection between excessive $\mathrm{Cu}$ accumulation and hepatobiliary malignancies, ${ }^{19-21}$ multiple clinical investigations observed elevated serum ${ }^{22-25}$ and intratumoral ${ }^{26-28} \mathrm{Cu}$ levels in liver cancer patients. Notably, $\mathrm{Cu}$ lies at a unique intersection between chemistry and biology, as Cu-driven redox chemistry is required for a multitude of biological programs. To minimize oxidative damage, $\mathrm{Cu}$ homeostasis is a highly regulated process, beginning when $\mathrm{Cu}$ enters the cell through the essential copper transporter 1, CTR1. ${ }^{29,30}$ CTR1 is the predominant high-affinity $\mathrm{Cu}$ transporter at the plasma membrane, while its low-affinity homolog, CTR2, localizes and facilitates transport from vesicular compartments into the cytoplasm. ${ }^{31,32}$ To complement $\mathrm{Cu}$ influx via CTR1, cells are also equipped with Cu efflux machinery. Specifically, the P-type ATPases ATP7A and ATP7B are membranebound transport pumps that function to export cytosolic $\mathrm{Cu}$ in an ATP-dependent fashion. ${ }^{33,34}$ The importance of maintaining a balance between $\mathrm{Cu}$ influx and efflux is clear given that deletions in CTR1 lead to embryonic lethality, while mutations in ATP7A and $A T P 7 B$ manifest in Menkes or Wilson disease, respectively. Interestingly, emerging evidence indicates that regulation of $\mathrm{Cu}$ homeostasis coincides with other cellular processes, from lipid metabolism ${ }^{35}$ to cellular proliferation. ${ }^{36}$ Our lab has discovered that $\mathrm{Cu}$ can enhance oncogenic signaling in the MAPK pathway via a direct interaction with MEK1 and MEK2, resulting in a $\mathrm{Cu}$ dependency in mutant BRAF ${ }^{\mathrm{V} 600 \mathrm{E}}$ positive melanoma. ${ }^{37}$ Similarly, $\mathrm{Cu}$ is required for the activity of the autophagic kinases ULK1 and
ULK2 and autophagosome formation downstream of ULK1 and ULK2 is sensitive to fluctuations in Cu availability. ${ }^{38}$ Collectively, these findings create a molecular foundation that directly links $\mathrm{Cu}$ homeostasis to deregulated signal transduction events that drive pathological conditions. However, the contribution of $\mathrm{Cu}$ to intrinsic and extrinsic cellular mechanisms necessary for liver tumorigenesis and resistance driven by treatment-mediated metabolic reprogramming in HCC patients remains unclear.

In the current study, we sought to bridge this gap by taking a bioinformatic approach utilizing publicly available cancer genome datasets. We evaluated the expression of $\mathrm{Cu}$ homeostasis genes, namely those facilitating $\mathrm{Cu}$ transport such as $A T P 7 A, A T P 7 B, S L C 31 A 1$, which encodes CTR1, and SLC31A2, which encodes CTR2, across HCC and normal tissue samples. From this analysis, we identified significant alterations in the aforementioned $\mathrm{Cu}$ transporter genes, and further, found that copy number variations in the $\mathrm{Cu}$ transporters correlated with poorer survival and disease-free progression, and was associated with increased $\mathrm{Cu}$ levels. Given the importance of $\mathrm{Cu}$ modulation in disease management, the manipulation of $\mathrm{Cu}$ homeostasis has been previously exploited as an alternative cancer therapy through the usage of various $\mathrm{Cu}$ chelating agents. ${ }^{37,39-41}$ We explored the relevance of perturbed $\mathrm{Cu}$ availability, through genetic ablation of CTR1 or pharmacologic inhibition via tetrathiomolybdate (TTM), in HCC. Here we demonstrate that targeting $\mathrm{Cu}$ homeostasis exposes a unique vulnerability in HCC, as we discovered $\mathrm{Cu}$-dependent contributions to both the glycolytic metabolism and the tumorigenic properties of HCC.

\section{Methods}

\section{Data mining}

$A T P 7 A, A T P 7 B, S L C 31 A 1$, or SLC31A2 mRNA expression in normal or tumor liver tissue samples was obtained from the Gene Expression across Normal and Tumor tissue (GENT2) web-based genome database (http://gent2.appex.kr/gent2/, Korean Research Institute and Biotechnology). A total of 1095 patients and 1089 samples across six hepatocellular adenoma or carcinoma data sets [Memorial Sloan Kettering (MSK), Clin Cancer Res 2018; INSERM, Nat Genet 2015; MSK, PLOS One 2018; AMC, Hepatology 2014; RIKEN, Nat Genet 2012; The Cancer Genome Atlas (TCGA), Firehorse Legacy] were selected for query from cBioportal for $A T P 7 A, A T P 7 B, S L C 31 A 1$, or $S L C 31 A 2$ copy number alterations and patient survival data. For overall survival plot, $n=13$ patients with altered copy number of $\mathrm{Cu}$ transporters and $n=594$ for patients with unaltered copy number $\mathrm{Cu}$ transporters. For disease-free progression, $n=11$ patients with altered copy number of $\mathrm{Cu}$ transporters and $n=545$ for patients with unaltered copy number $\mathrm{Cu}$ transporters.

\section{ICP-MS sample preparation of human HCC cell lines and rat liver tissue}

Human HCC cell lines were seeded at $2.0 \times 10^{6}$ cells in $100 \mathrm{~mm}$ dishes. After incubation for 48 hours in either $21 \% \mathrm{O}_{2}$ or $1 \% \mathrm{O}_{2}$, cells were washed twice and harvested with $1 \times$ Phosphate 
Buffered Saline. Cell pellets were collected by centrifugation at $2000 \times g$ for 5 minutes, and were flash-frozen in a dry ice-ethanol bath prior to storing at $-80{ }^{\circ} \mathrm{C}$. HCC tumors and adjacent liver tissues were harvested from the livers of Wistar rats subjected to the dietylnitrosamine-induced (DEN) diet according to an established protocol. ${ }^{42}$ Tissue samples were harvested, weighed, flash-frozen in a dry ice-ethanol bath, and immediately stored at $-80{ }^{\circ} \mathrm{C}$. All samples were processed by the PADLS New Bolton Center Toxicology Laboratory in the School of Veterinary Medicine at the University of Pennsylvania.

\section{X-ray fluorescence microscopy}

For XFM experiments $10 \mu \mathrm{m}$ sections were transferred to Ultralene ${ }^{\circledR}$, a XFM compatible window material, mounted on in-house developed lucite sample holders and air-dried. XFM data were collected on beamline 2-ID-E at the Advanced Photon Source (APS), Argonne National Laboratory, Argonne, IL. The incident X-ray energy was tuned to $10 \mathrm{keV}$ using a Si-monochromator and focused with a Fresnel zone plate. X-ray fluorescence was collected using an energy dispersive 4-element detector (Vortex ME-4, SII Nanotechnology, Northridge, CA). Raster scans were collected in fly-scan mode, using $1 \mu \mathrm{m} \times 1 \mu \mathrm{m}$ step size with $200 \mathrm{~ms}$ dwell time per point. 2-Dimensional elemental maps were created by extracting, background subtracting, and fitting the fluorescence photon counts at each point using the program MAPS. ${ }^{43}$ The fluorescent counts were transformed into $\mu \mathrm{g} \mathrm{cm}^{-2}$ using calibrated X-ray standards (AXO products, Dresden, Germany). Quantitative analysis was performed by extracting the fluorescent spectra and fitting and quantifying them against the calibration standards as mentioned above. Area concentrations were converted into volume concentrations using the tissue thickness of $10 \mu \mathrm{m}$ under the assumption that the X-ray beam fully penetrated the sample.

\section{Cell lines \& cell culture}

SNU387, SNU398, and SNU449 HCC cell lines and human plateable hepatocytes, 5-donor were obtained from the American Type Culture Collection (ATCC) and ThermoFisher Scientific, respectively. Parental cell lines were cultured in Roswell Park Memorial Institute (RPMI 1640, Gibco) Media and supplemented with 10\% v/v fetal bovine serum (FBS, GE Lifesciences), $100 \mathrm{U} \mathrm{mL}^{-1}$ penicillin, and $100 \mu \mathrm{g} \mathrm{mL} \mathrm{m}^{-1}$ streptomycin (Gibco). SNU398 and SNU449 cell lines stably expressing the pLKO.1puro constructs were maintained as above supplemented with $5 \mu \mathrm{g} \mathrm{mL}^{-1}$ puromycin (Invitrogen). SNU398 and SNU449 were stably infected with lentiviruses derived from the pLKO.1 plasmid (see plasmids below) using established protocols. Unless specified, all cell lines were maintained in a humidified Heracell (ThermoFischer Scientific) incubator set to $37{ }^{\circ} \mathrm{C}$ and $5 \% \mathrm{CO}_{2}$. For hypoxic cell culture, cells were maintained at $37{ }^{\circ} \mathrm{C}$ and $1 \% \mathrm{O}_{2}$ in Whitley $\mathrm{H} 35$ Hypoxystation (Don Whitley Scientific). MycoAlert ${ }^{\mathbb{R}}$ mycoplasma test detection kit (Lonza, LT07-418) was used to test for mycoplasma contamination.

\section{Immunoblot analysis}

The indicated HCC cell lines were washed with cold $1 \times$ phosphate-buffered saline (PBS), and lysed in cold RIPA buffer supplemented with $1 \times$ EDTA-free Halt ${ }^{\mathrm{TM}}$ protease and phosphatase inhibitor cocktail (ThermoFisher Scientific, \#78441). Total protein was quantified using the BCA assay (Pierce, \#PI23228), where sample concentrations were interpolated to a BSA standard curve. Equivalent amounts of lysate were resolved by SDSPAGE using lab established protocols, and protein was detected using the following antibodies (dilution, catalog\#, manufacturer): rabbit anti-CCS $(1: 2000,20141$, Santa Cruz) or mouse anti- $\beta$-actin (1:5000, 3700, Cell Signaling Technologies (CST)), followed by detection with one of the following horseradishperoxidase-conjugated secondary antibodies: goat anti-mouse IgG $(1: 4000,7076, \mathrm{CST})$ or goat anti-rabbit IgG $(1: 4000,7074$, CST) using SignalFire ECL (CST, \#6883S) detection reagents.

\section{Plasmids}

pLKO.1puro lentiviral shRNA plasmids were obtained from High-Throughput Screening Core at the University of Pennsylvania to express: nontargeted control $(\operatorname{sh} S C R)$, human CTR1 target sequence \#1 5'-GATGCCTATGACCTTCTACTT-3' (shCTR1\#1), or human CTR1 target sequence \#2 5'-CGGTACAGGATACTTCCT CTT-3' (shCTR1\#2).

\section{RT-qPCR}

To examine the expression of $\mathrm{Cu}$ transporter and glycolytic genes, $3.0 \times 10^{5}$ cells of the indicated HCC cells were seeded into $60 \mathrm{~mm}$ dishes. Sixteen hours post-seeding, cells were treated with the indicated concentrations of TTM and/or were moved to hypoxic conditions for 48 hours. To isolate RNA, cells were harvested in TRIzol $^{\mathrm{TM}}$ reagent (Invitrogen, \#15596018) and RNA was extracted following manufacturer's protocol. Purified RNA was reverse transcribed (RT) into cDNA using the Applied Biosystems $^{\mathrm{TM}}$ Taqman $^{\mathrm{TM}}$ Reverse Transcription Reagents (Applied Biosystems, \#N8080234) and corresponding protocol. Subsequent cDNA was loaded onto a clear 384-well plate (Genesee, \#24-305) and quantified on a ViiA 7 Real-Time PCR System with standard protocols using the following Taqman $^{\mathrm{TM}}$ probes: Hs00163707_m1 to detect human ATPase copper transporter A (ATP7A), Hs01075310_m1 to detect human ATPase copper transporter B (ATP7B), Hs00977266_g1 to detect human SLC31A1 (CTR1), Hs00156984_m1 to detect human copper transporter 2 SLC31A2 (CTR2), Hs00761782_s1 to detect human pyruvate kinase muscle isoform (PKM), Hs01378790_g1 to detect human lactate dehydrogenase A ( $L D H A)$, Hs00892681_m1 to detect human glucose transporter 1 (GLUT1), and Hs00427620_m1 to detect human TATA-binding proteins $(T B P)$. The $\Delta 2^{-C_{\mathrm{t}}}$ or comparative $\Delta \Delta C_{\mathrm{t}}$ method was used as described previously ${ }^{44}$ to analyze mRNA after transcript levels were normalized to TBP. For validation of CTR1 knock-down, cells transduced with shRNA targeting CTR1 were harvested and processed as above upon selection with puromycin, and then assayed for relative CTR1 expression following the procedure above.

\section{Reagents}

The Cu chelator TTM (\#323446) and the crystal violet (\#C0775$100 \mathrm{G})$ used for colony staining were purchased from SigmaAldrich. 


\section{Clonogenic assay}

SNU398 and SNU449 cell lines stably expressing indicated constructs were seeded at $3.0 \times 10^{3}$ cells per well in six-well plates. After incubation for seven days, cells were washed once with $1 \times$ Phosphate Buffered Saline (PBS) and stained with $1 \mathrm{~mL}$ of a crystal violet staining solution $(0.5 \% \mathrm{w} / \mathrm{v}$ crystal violet $(\mathrm{CV})$, $20 \% \mathrm{v} / \mathrm{v}$ methanol, distilled water) for 15 minutes. After 15 minutes, all wells were washed three times with distilled water to minimize background staining. CV stained colonies were imaged using a ChemiDoc Touch Imagining System (Bio-Rad). To quantify colony abundance, stained cell colonies were dissolved in a 10\% acetic acid solution for 30 minutes at room temperature, and extracted CV was measured at an absorbance of $590 \mathrm{~nm}$ in a plate reader (Synergy, BioTek). For TTM treatments, cells were treated 24 hours after seeding with either a vehicle or a final indicated concentration of TTM for seven days and then processed as mentioned above. For hypoxia $\left(1 \% \mathrm{O}_{2}\right)$ exposures, cells were seeded in normoxic $\left(21 \% \mathrm{O}_{2}\right)$ conditions for 24 hours, and then moved to the hypoxic condition where pre-equilibrated hypoxic media was applied for the remainder of the seven-day incubation time.

\section{Measurement of cell proliferation with trypan blue}

SNU398 and SNU449 cell lines stably expressing the indicated constructs were seeded at $1.5 \times 10^{4}$ cells per well in a six-well plate on Day 0. Proliferation curves using cell lines stably expressing indicated constructs in the presence or absence of TTM were performed at identical times. On Day 1, DMSO or TTM treatment was added to a final concentration of $25 \mu \mathrm{M}$. Cell counts were performed every other day by washing cells with $1 \times$ PBS, detaching cells with $0.05 \%$ Trypsin (Gibco, \#25300054). Cells were then resuspended in an equal volume of complete DMEM, and centrifuged at $1000 \times g$ for $5 \mathrm{~min}$. Following aspiration of media, cell pellets were then resuspended in identical volumes of complete DMEM. Cell counting was performed using an automated cell counter (Invitrogen Cell Countess II) by taking an aliquot of cell culture and diluting 1:1 with 0.4\% Trypan Blue Solution (Life Technologies/Invitrogen, \#15250061) before plating on and reading with a hemocytometer.

\section{Anchorage-independent growth on ultra-low attachment plates}

SNU398 and SNU449 cell lines stably expressing the indicated constructs were seeded at $2.0 \times 10^{3}$ cells per well in a 96-well clear flat bottom ultra-low attachment plates (Corning, \#3474) on Day 0. For the TTM-treated groups, indicated concentrations of TTM were added 16 hours post-seeding. On Day 5, cells were imaged using an EVOS XL Core Imaging System brightfield microscope with a $\times 10$ dry objective. The mean number of spheroids (cells) per field was quantified by a researcher blinded to the genetic manipulations or TTM treatment groups using Fiji software (https://imagej.net/Fiji). Data was normalized to the respective control $(\mathrm{sh} S C R)$ or vehicle-treated (DMSO) control group.

Measurement of ATP using CellTiter-Glo ${ }^{\circledR}$ viability assay

SNU398 and SNU449 cell lines stably expressing indicated constructs were seeded in triplicate at $5.0 \times 10^{2}$ cells per well in 96-well white walled flat bottom plates (Fisher Scientific, \#655098) or 96-well clear flat bottom ultra-low attachment plates for $\mathrm{IC}_{50}$ determinations in anchorage-dependent (2D) or anchorageindependent (3D) conditions, respectively. Sixteen hours postseeding, indicated concentrations of TTM were added to appropriate wells and cells were incubated for 72 hours. Cell viability was assessed using the CellTiter-Glo ${ }^{\circledR}$ Luminescent (Promega, \#G7572) or 3D (Promega, \#9682) Cell Viability Assay for 2D or 3D conditions, respectively, following the manufacturer's protocol. Normalized \%ATP values were calculated by normalizing the raw luminescent values of wells containing the vehicle (DMSO) to wells containing each dose of TTM. To determine the $\mathrm{IC}_{50}$ values, the data was transformed using the nonlinear fit of Log(TTM) versus normalized response (\%ATP Normalized to DMSO) with a variable slope function in GraphPad Prism8 software.

\section{Measurement of glucose consumption and lactate production}

To determine relative glucose consumption and lactate production, $3.0 \times 10^{5}$ cells of the indicated HCC cells were seeded into $60 \mathrm{~mm}$ dishes (GenClon, \#25-260). Approximately 16 hours post-seeding, cells were treated with indicated concentrations of TTM for 48 hours. For hypoxic conditions, cells were moved to the hypoxic condition where pre-equilibrated hypoxic media was applied for the 48 hour incubation time. Both spent media, collected upon completion of the incubation time, and fresh media, collected at the start of the experiment, were harvested from cell cultures, and following a brief centrifugation $(500 \times g$ for five minutes), supernatant was transferred to a fresh Eppendorf tube, flash frozen on an ethanol-dry ice bath, and stored at $-80{ }^{\circ} \mathrm{C}$ until further processing. Glucose consumption and lactate production were measured using a YSI2950 immobilized enzyme analyzer from YSI Life Sciences. Prior to sample analysis, the linearity of the analyzer was calibrated using standards from the manufacturer. Metabolite consumption or production was calculated following the cell number area under the curve normalization as previously described. ${ }^{45}$ Briefly, metabolite consumption is defined as $v=V\left(x_{\text {fresh medium }}-x_{\text {spent medium }}\right) / A$, where $v$ is glucose consumption or lactate production, $V$ is the culture volume used, $x$ is the metabolite concentration, and $A$ is the cell number area under the curve. $A$ is obtained by integrating the final cell count and doubling time across the duration (time) of the experiment. Initial and final cell counts used to determine $A$ were obtained using an automated cell counter.

\section{Statistical analysis}

Data are reported as mean \pm s.e.m. Each sample size $(n)$ represents biologically independent experiments or fields of view. For biologically independent experiments, data was collected from three independent experiments unless otherwise specified within the figure legend. For fields of view, data presented are from 9 fields of view taken from three biologically independent experiments. Statistical significance was determined using an unpaired one- or two-tailed Student's $t$-test, a Mantel-Cox test, a one-way or two-way ANOVA followed by Dunnett's or Tukey's multiple comparisons test, where significance was defined as $P \leq 0.05$. All statistical analysis was performed in GraphPad Prism 8 software. 


\section{Results}

Expression of $\mathrm{Cu}$ transporters is dysregulated in hepatocellular carcinoma

Clinical measurements of transition metals demonstrated that HCC tumors exhibit elevated $\mathrm{Cu}$ levels when compared to normal liver tissue $^{27}$ and higher serum $\mathrm{Cu}$ levels correlate with the presence of cirrhosis or HCC. ${ }^{24}$ In agreement, Wilson disease patients accumulate $\mathrm{Cu}$ in the liver and exhibit cirrhosis and thus, have a higher propensity to develop HCC. To further investigate these clinically relevant observations that connect $\mathrm{Cu}$ to $\mathrm{HCC}$ development, ${ }^{15-18,24,27}$ we examined the expression of $\mathrm{Cu}$ influx and efflux transporters across human liver cancer and normal liver tissue utilizing the Gene Expression database of Normal and Tumor tissues 2 (GENT2). We found that mRNA expression of both $\mathrm{Cu}$ transporters SLC31A1 and $S L C 31 A 2$, along with the $\mathrm{Cu}$ exporter $A T P 7 B$ was significantly lower, while the mRNA expression of the $\mathrm{Cu}$ exporter ATP7A was significantly higher in liver cancer (Fig. 1a and b). Intrigued by this finding, we investigated the relationship between patient survival and copy number alterations of $\mathrm{Cu}$ transporter loci in six HCC patient data sets in cBioPortal. Although a small cohort, HCC patients with copy number alterations of $\mathrm{Cu}$ influx or efflux transporters had a significantly worse outcome with respect to overall survival and likelihood of recurrence (Fig. 1c and d). Taken together, these data suggest that $\mathrm{Cu}$ transport into or out of the cell is dysfunctional in a subset of HCC patients. Consistent with clinical findings, we observed elevated $\mathrm{Cu}$ levels in HCC tumors compared to adjacent liver tissue collected from a DEN-induced rat model of HCC using inductively coupled plasma mass spectrometry (ICP-MS) (Fig. 1e). Closer examination of the $\mathrm{Cu}$ concentration in the rat liver tumor tissue with X-Ray Fluorescence Microscopy (XFM), revealed heterogeneous $\mathrm{Cu}$ concentration. In an example shown in Fig. 1f from HCC rat tumor tissue, $\mathrm{Cu}$ was localized to highly concentrated focal areas of approximately 10 to $15 \mu \mathrm{m}$ diameter that exceeded $5 \mathrm{mg} \mathrm{g}^{-1}$ ( $\sim 80 \mathrm{mM}$ ), while the average concentration across the scan was $40 \mu \mathrm{g} \mathrm{g}^{-1}(\sim 60 \mu \mathrm{M})$. To establish a model that is more amenable to genetic and pharmacologic perturbations, we measured total intracellular $\mathrm{Cu}$ levels using ICP-MS from a panel of human HCC cell lines (Fig. 19). In agreement with the rodent model data, HCC cell lines exhibited significant elevation in Cu levels when compared to a primary hepatocyte line, HMCPP. Recognizing that $\mathrm{Cu}$ transporters mediate cellular $\mathrm{Cu}$ influx and efflux, we investigated whether there was evidence of differential $\mathrm{Cu}$ transporter expression as measured by quantitative PCR (qPCR) (Fig. 1h). Interestingly, mRNA expression of $A T P 7 B, S L C 31 A 1$, and $S L C 31 A 2$ was significantly lower in HCC cells, which parallels the observations made from patient genomic data sets (Fig. 1a and b). Further, elevated $\mathrm{Cu}$ levels were confirmed by lower protein expression of CCS, which is degraded in a Cu-dependent fashion, ${ }^{46}$ in all of the HCC cell lines when compared to normal hepatocytes (Fig. 1i), suggesting that HCC cells accumulate excess $\mathrm{Cu}$ levels that may contribute to oncogenic properties.

\section{Genetic depletion of CTR1 diminished HCC tumorigenic properties}

To interrogate whether these increased $\mathrm{Cu}$ levels are essential for HCC tumorigenic properties, we generated stable genetic knockdown of CTR1 with two independent short-hairpin RNAs (shRNA) targeting the SLC31A1 gene in both SNU398 and SNU 449 cells, as measured by qPCR (Fig. 2a and b). Disruption of CTR1 significantly reduced the proliferation of SNU398 and SNU449 cells (Fig. 2c and d). In addition to cellular proliferation, colony formation of SNU398 and SNU449 cells when plated at low density, a property that distinguishes tumorigenic cells from healthy cells, was dependent on CTR1 expression (Fig. 2e and f). Furthermore, patients with HCC may develop metastases which requires detachment from the extracellular matrix and invasion into nearby organs. ${ }^{47}$ Thus, to complement our findings of reduced HCC proliferation and colony formation in the context of CTR1 deficiency, ultra-low attachment (ULA) polystyrene plates were used to evaluate the effects of CTR1 depletion on anchorageindependent growth in SNU398 and SNU449 cells. Knockdown of CTR1 significantly diminished the anchorage-independent growth of SNU398 and SNU449 cells (Fig. $2 \mathrm{~g}$ and h). Taken together, these findings demonstrate that HCC cell lines depend on $\mathrm{Cu}$ transport via CTR1 for proliferation, colony formation, and anchorage-independent growth, suggesting that altered $\mathrm{Cu}$ availability contributes to hepatocarcinogenesis.

\section{TTM treatment attenuated HCC proliferation and anchorage-independent growth}

The repurposing of TTM, a Cu-specific chelator used in the treatment of Wilson disease, has been explored as a cancer therapy in several contexts. ${ }^{39,41,48,49}$ Mechanistically, preclinical studies and phase I/II clinical trials suggest that $\mathrm{Cu}$-dependent components of the tumor microenvironment, ${ }^{41}$ oncogenic kinase signaling pathways, ${ }^{38,49,50}$ and metabolic pathways ${ }^{51}$ mediate sensitivity to TTM. ${ }^{40,41}$ Considering that HCC tumors are well-vascularized ${ }^{52}$ and demonstrate amplified receptor tyrosine kinase signaling ${ }^{4}$ as well as a dependency on glycolytic metabolism, ${ }^{53,54}$ we hypothesized that disruption of $\mathrm{Cu}$ accessibility through pharmacological interventions would diminish HCC tumorigenic properties. To begin evaluating this hypothesis, SNU398 and SNU449 cells were treated with increasing concentrations of TTM and then cell viability was measured using a high-throughput luminescent-based assay that detects ATP. TTM treatment decreased ATP, and thus viability of SNU398 and SNU449 cells, in a dose-dependent manner (Fig. 3a-c). To determine whether TTM would remain as efficacious in $3 \mathrm{D}$ cultures, the $\mathrm{IC}_{50}$ of TTM-treated SNU398 and SNU449 cells seeded in ULA plates was determined (Fig. 3d-f). Interestingly, there was nearly a two-fold and three and a half-fold increase in the $\mathrm{IC}_{50}$ concentration of TTM from 2D to 3D cultures in SNU398 cells and SNU449 cells, respectively (Fig. 3c and f). This finding is in agreement with other observations that HCC cells grown in 3D have enhanced drug-resistance and aggressiveness as compared to their 2D counterparts. ${ }^{55}$ In accordance, when treated with TTM at a concentration at or above the $\mathrm{IC}_{50}$, SNU398 and SNU449 cells still exhibited reduced proliferation as measured by trypan blue exclusion staining (Fig. $3 \mathrm{~g}$ and $\mathrm{h}$ ). Moreover, when cultured with increasing concentrations of TTM in anchorage-independent conditions, spheroid formation was significantly reduced in SNU449 cells and trended downwards in SNU398 cells (Fig. 3i and j). 
a

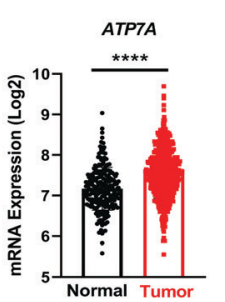

SLC31A1

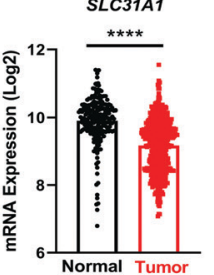

e
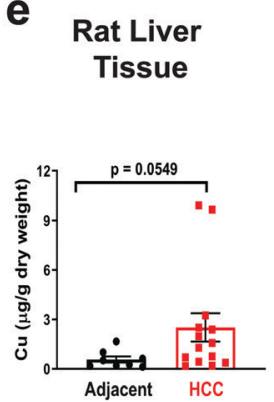

h

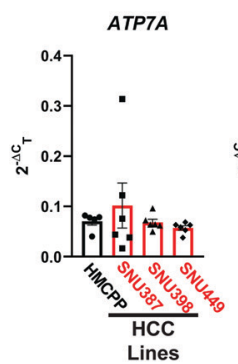

Liver Cancer

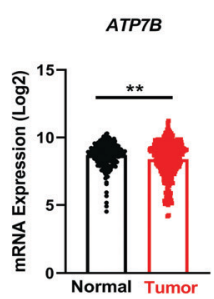

SLC31A2

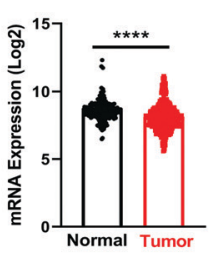

b

\begin{tabular}{ccccc|} 
Gene Name & $\begin{array}{c}\text { Mean Normal } \\
\text { Tissue mRNA } \\
\text { Expression } \\
\text { (Log2) }\end{array}$ & $\begin{array}{c}\text { Mean Tumor } \\
\text { Tissue mRNA } \\
\text { Expression } \\
\text { (Log2) }\end{array}$ & P-value & $\begin{array}{c}\text { Log2 } \\
\text { Fold- } \\
\text { Change }\end{array}$ \\
\hline ATP7A & 7.169 & 7.543 & $<0.0001$ & 0.3748 \\
\hline ATP7B & 8.892 & 8.397 & 0.0018 & -0.2958 \\
\hline SLC31A1 & 9.908 & 9.171 & $<0.0001$ & -0.7369 \\
\hline SLC31A2 & 8.609 & 8.104 & $<0.0001$ & -0.5055 \\
\hline
\end{tabular}

C

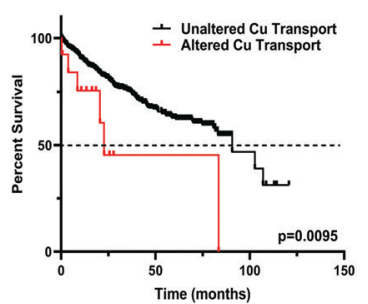

d

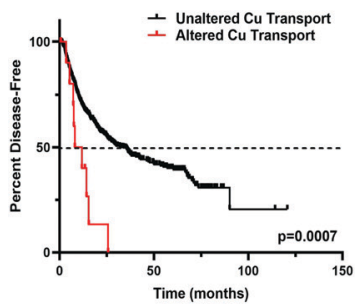

f
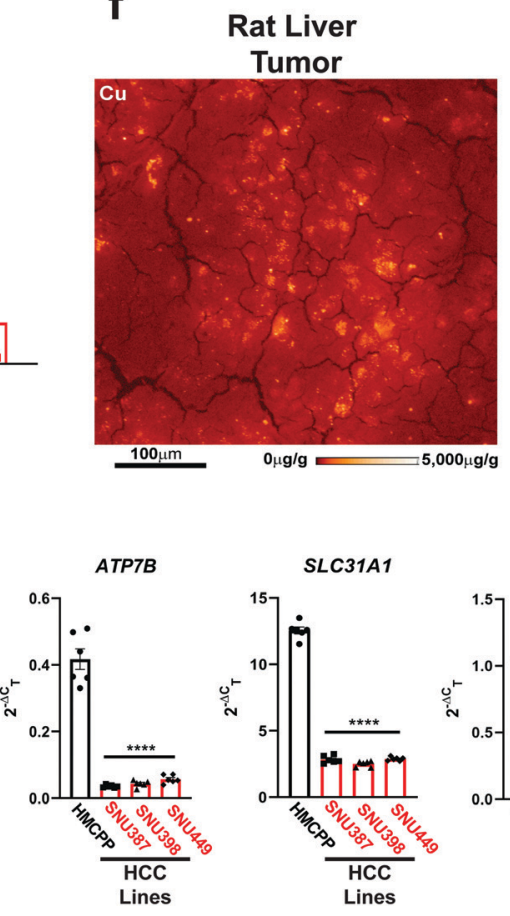

g

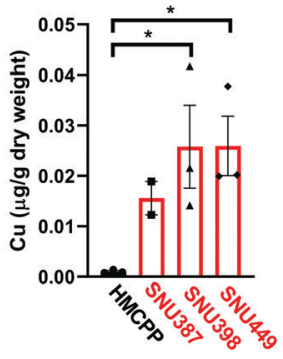

i

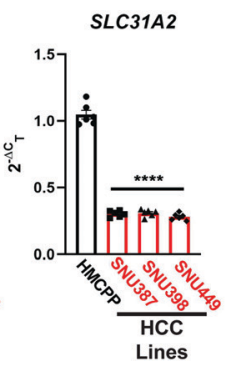

HCC Lines

Fig. 1 Aberrant Cu homeostasis is observed in liver cancer and specifically in HCC. (a) Scatter dot plot with bar at mean \pm s.e.m. of $m R N A$ expression of ATP7A, ATP7B, SLC31A1 (CTR1), and SLC31A2 (CTR2) from normal and tumor liver tissue samples from the online, open-access database GENT2.

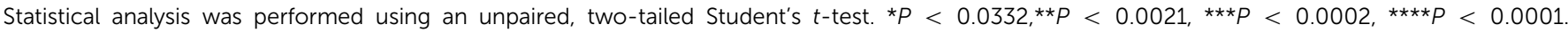
(b) Summary table of mRNA expression data shown in (a). (c and d) Kaplan-Meier analysis of overall survival (c) and disease-free progression (d) with median (dashed black lines) from HCC patients with either altered (solid red lines) or unaltered (solid black lines) copy number of Cu transporter genes mentioned in (a) and (b). For overall survival plot, $n=25$ patients with altered and $n=582$ for patients with unaltered copy number of Cu transporter genes. For disease-free progression, $n=20$ patients with altered expression and $n=536$ for patients with unaltered copy number of Cu transporter genes. Results were compared using a Mantel-Cox test. ${ }^{*} P<0.0332,{ }^{* *} P<0.0021$. (e) Scatter dot plot of inductively coupled plasma mass spectrometry (ICP-MS) detection with bar at mean $\mathrm{Cu}\left(\mu \mathrm{g} \mathrm{g}^{-1}\right.$ dry weight) from HCC tumors or adjacent liver tissue from rats per sample dry weight \pm s.e.m. $n=8$ adjacent liver tissue or $n=14 \mathrm{HCC}$ tumors. Results were compared using an unpaired, one-tailed $t$-test. ( $\mathrm{f}$ ) XFM elemental distribution for Cu of a representative tumor section. The sections was scanned with $1 \mu \mathrm{m}$ spot size in $x$ and $y$. Elemental concentrations are shown using false coloring (red temperature, logarithmic scale). (g) Scatter dot plot of ICP-MS detection with bar at mean $\mathrm{Cu}$ ( $\mu \mathrm{g} \mathrm{g}^{-1}$ dry weight) from human liver cell lines per sample dry weight \pm s.e.m. $n=3$ biologically independent samples. Results were compared using a one-way ANOVA followed by a Tukey's multiplecomparisons test where ${ }^{*} P<0.0332$. (h) Scatter dot plot with bar at mean \pm s.e.m. of $\Delta 2^{-C t}$ normalized quantitative PCR (qPCR) expression of $A T P 7 A$, ATP7B, SLC31A1, and SLC31A2 mRNA from normal liver cells (HMCPP) or HCC cell lines (SNU387, SNU398, SNU449) (i) Immunoblot detection of CCS or $\beta$-Actin from normal liver cells (primary hepatocytes) or HCC cell lines (SNU398, SNU449, or SNU387). $n=1$ biologically independent experiment. 


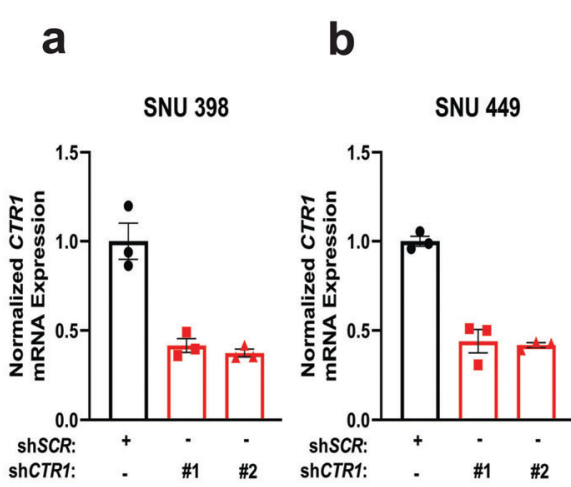

e ShRNA:
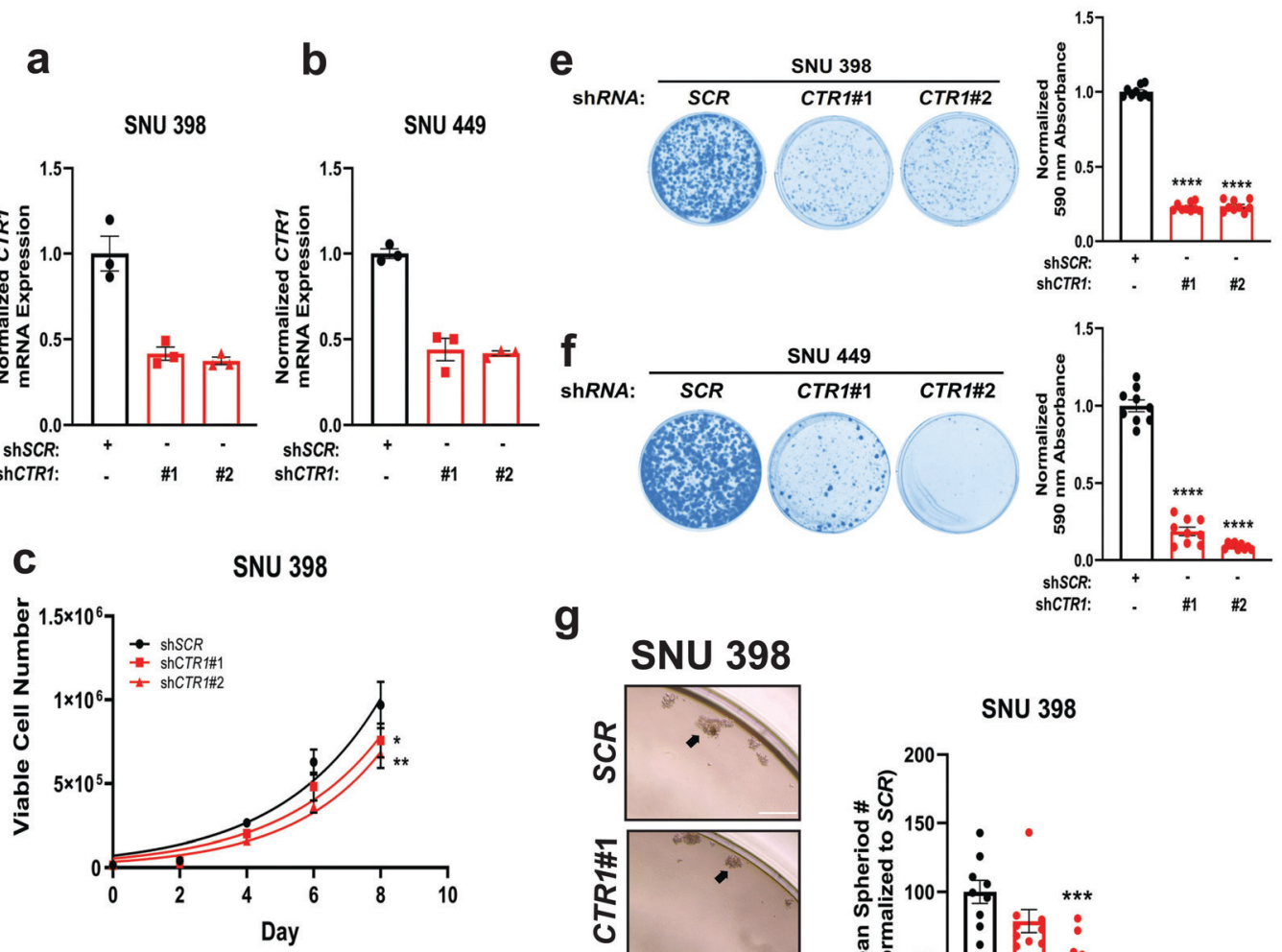

g
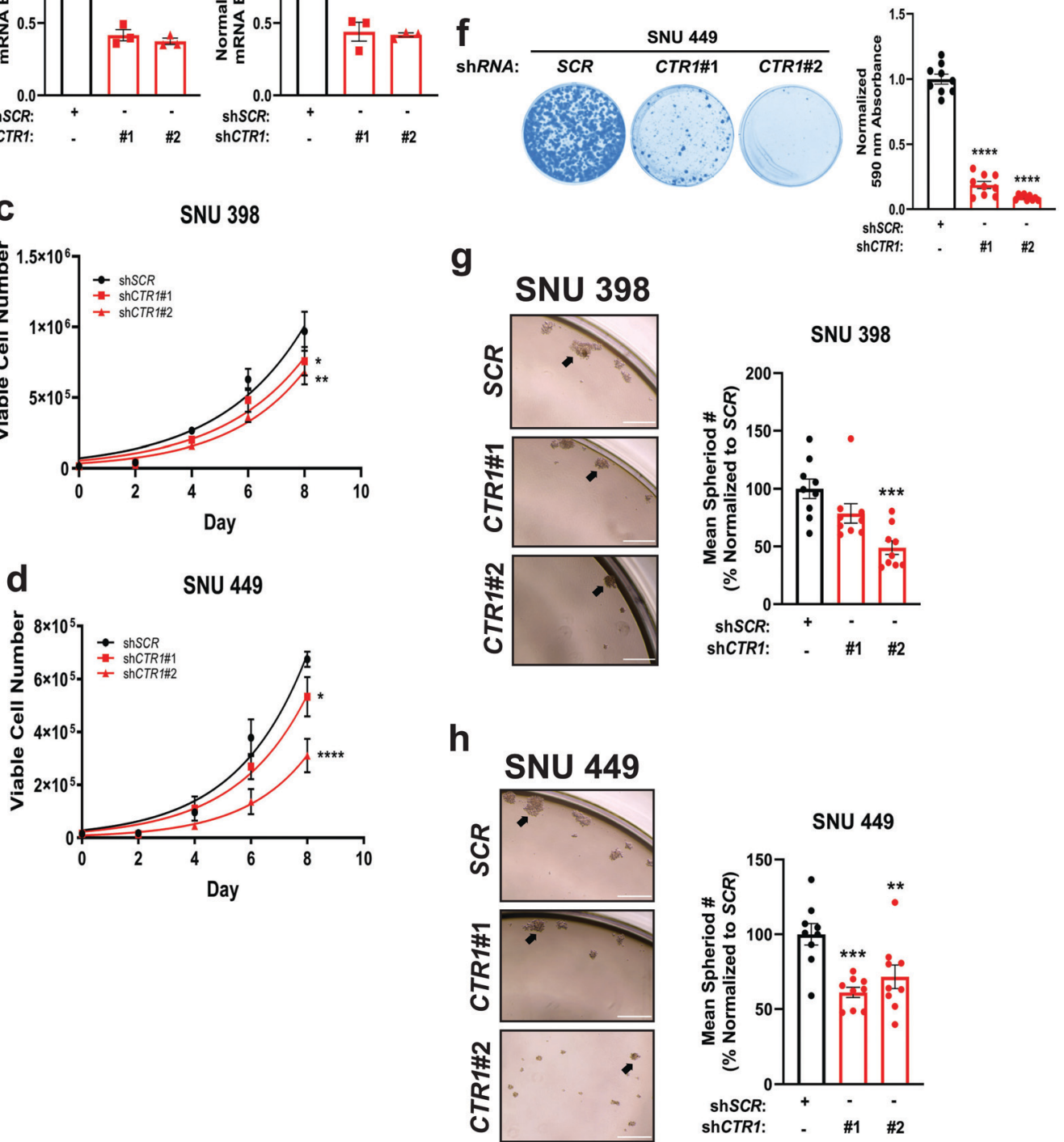

Fig. 2 Loss of the major Cu transporter CTR1 reduces tumorigenic properties of HCC. (a and b) Scatter dot plot with bar at mean \pm s.e.m. of normalized quantitative PCR (qPCR) expression of CTR1 mRNA from SNU398 (a) and SNU449 (b) HCC cell lines stably expressing shRNA against CTR1 or a nontargeting scramble sequence $(S C R) . n=1$ biologically independent experiment performed in technical triplicate. (c and d) Non-linear fit to the exponential growth equation of cellular proliferation from SNU398 $($ c) and SNU449 (d) HCC cell lines expressing shRNA against CTR1 or SCR. $n=3$ independent biological experiments, with each experiment plated in technical triplicate. Statistical analysis was performed using a two-way ANOVA followed by Dunnett's multiple comparison test. (e and f) Representative images (left) of crystal violet stained colonies from SNU398 (e) and SNU449 (f) HCC cells expressing shRNA against CTR1 or SCR, and scatter dot plot (bottom) of mean absorbance of extracted crystal violet at $590 \mathrm{~nm} \pm \mathrm{s}$.e.m. of crystal violet staining from three independent experiments plated in technical triplicate. The results were compared using a one-way ANOVA followed by Dunnett's multiple comparison test. ${ }^{\star} P<0.0332,{ }^{*} P<0.0021,{ }^{*} * * P<0.0002$, ${ }^{*} * \star * P<0.0001$. (g and h) Representative images of anchorageindependent growth in ultra-low attachment plates in SNU398 ( $\mathrm{g}$, left) or SNU449 (h, left) cell lines stably expressing ShRNA against CTR1 or SCR, with the normalized mean number of spheroids per field of view represented as a scatter dot plot for SNU398 (g, right) and SNU449 (h, right) from $n=9$ fields of view per condition from three independent biological experiments. Data was analyzed using a one-way ANOVA followed by Dunnett's multiple comparison test ${ }^{*} P<0.0332,{ }^{* \star} P<0.0021,{ }^{\star * \star} P<0.0002,{ }^{* \star \star \star} P<0.0001 .10 x$ magnification, scale bar $=400 \mu \mathrm{m}$. 
a

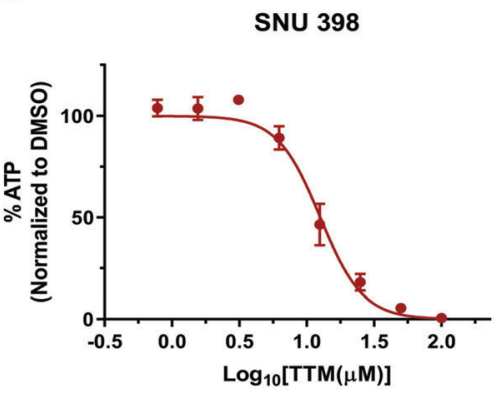

d

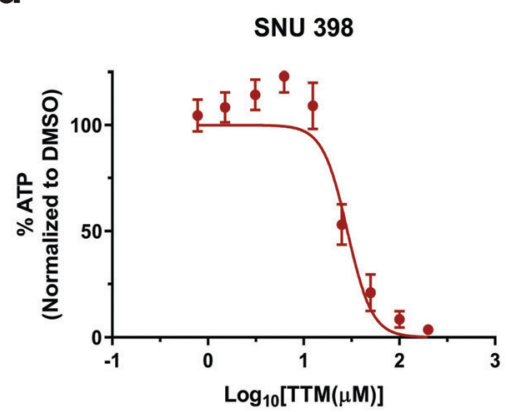

b

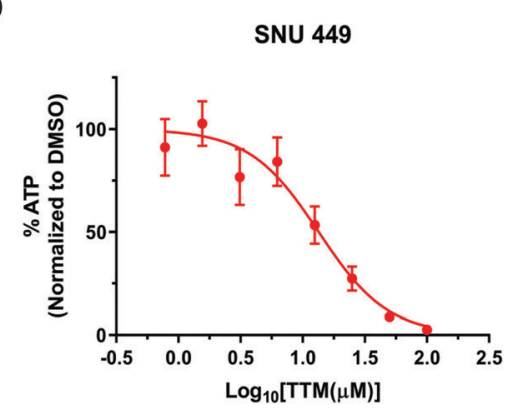

e

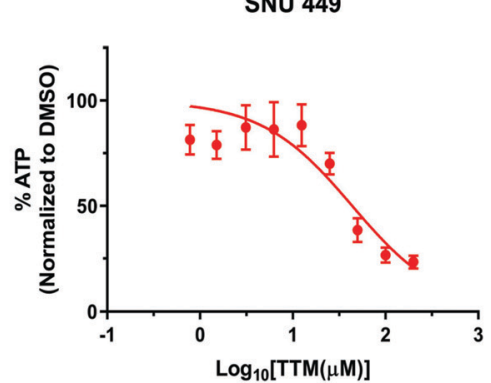

C

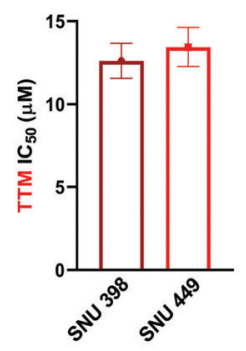

f

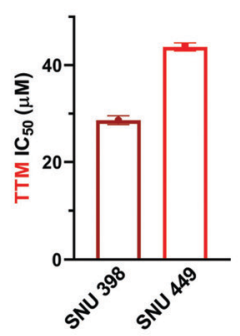

g

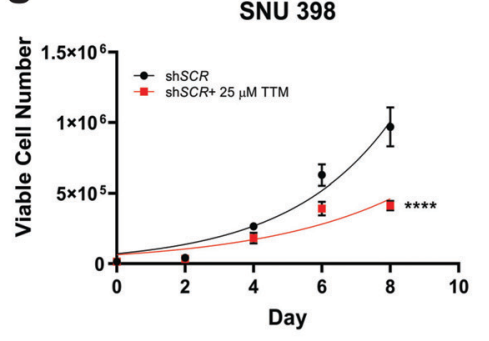

h

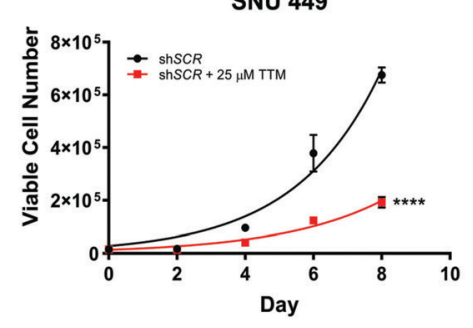

i

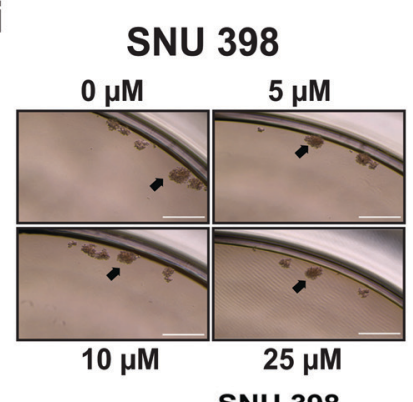

SNU 398

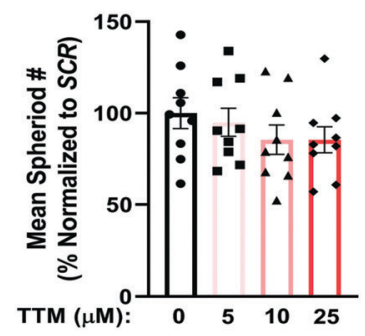

j $\quad$ SNU 449
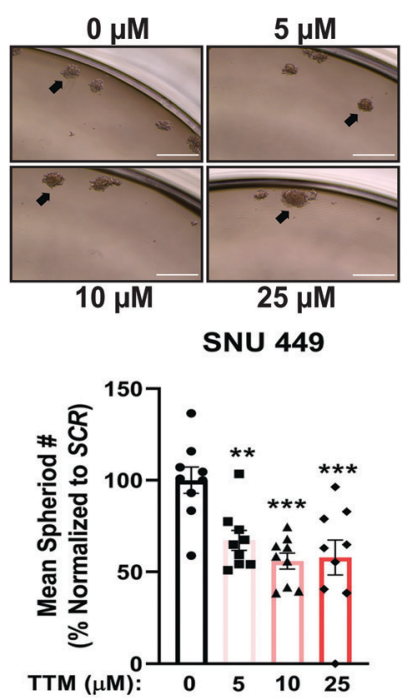

Fig. 3 TTM, a Cu specific chelator, hinders anchorage-dependent and anchorage-independent growth. (a and b) Relative CellTiter-Glo ${ }^{\mathbb{R}}$ cell viability \pm s.e.m. of SNU398 (a) or SNU449 (b) HCC cells treated with the indicated concentrations of TTM upon plating in anchorage-dependent (2D) conditions.

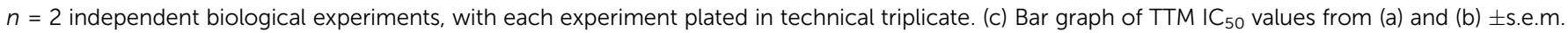
( $d$ and e) Relative CellTiter-Glo 3D ${ }^{\mathbb{R}}$ cell viability \pm s.e.m. of SNU398 (d) or SNU449 (e) HCC cells treated with the indicated concentrations of TTM upon seeding into ultra-low attachment (3D) plates. $n=3$ independent biological experiments, with each experiment plated in technical triplicate. (f) Bar graph of TTM IC 50 values from (d) and (e) \pm s.e.m. ( $\mathrm{g}$ and $\mathrm{h}$ ) Non-linear fit to the exponential growth equation of cellular proliferation from SNU398 (g) and SNU449 (h) cell lines, seeded side-by-side with cells in Fig. $2 \mathrm{c}$ and d, except treated with $25 \mu \mathrm{M}$ TTM. $n=3$ independent biological experiments, with each experiment plated in technical triplicate. Statistical analysis was performed using a two-way ANOVA followed by Dunnett's multiple comparison test. $\star \star \star \star P<0.0001$. (i and j) Representative images of anchorage-independent growth in ultra-low attachment plates in SNU398 (i, top) or SNU449 (j, top) cell lines treated with the indicated concentration of $\mathrm{TTM}$, with the normalized mean number of spheroids per field of view represented as a scatter dot plot for SNU398 (i, bottom) and SNU449 (j, bottom) from $n=9$ fields of view per condition from three independent biological experiments. Data was analyzed using a one-way ANOVA followed by Dunnett's multiple comparison test ${ }^{\star} P<0.0332,{ }^{\star *} P<0.0021,{ }^{\star \star *} P<0.0002,{ }^{* \star \star \star} P<0.0001 .10 \mathrm{x}$ magnification, scale bar $=400 \mu \mathrm{m}$. 
Collectively, these results are early indications that $\mathrm{Cu}$ chelation through TTM may be effective in reducing the properties that comprise HCC tumorigenesis.

\section{Genetic loss of CTR1 under hypoxic conditions hinders HCC metabolism}

Intriguingly, HCC cells adapt to accommodate the larger energy demands required for rapid growth and proliferation. HCC cells reprogram their glucose metabolism ${ }^{56}$ to fulfill these requirements at baseline and upon stress induced by the hypoxic environment driven by the metabolic zonation of the liver ${ }^{57}$ and treatmentinduced ischemia through TAE/TACE..$^{10,11,58,59}$ In the latter, oxygen-depleted conditions stabilize HIF-1, which induces the transcription of genes in multiple hypoxia response pathways. In particular, HIF-1 elevates the mRNA expression of genes that encode critical glycolytic proteins, such as glucose importer 1 (GLUT1), pyruvate kinase muscle isoform (PKM), and lactate dehydrogenase A (LDHA). It has been well-established that cells under hypoxia survive by relying on glycolytic metabolism to produce ATP. However, questions remain regarding the effects of $\mathrm{Cu}$ depletion in a hypoxic environment, which more closely recapitulates the glycolytic state of HCC cells under standard-ofcare TAE and TACE treatment. Given the requirement for elevated intracellular $\mathrm{Cu}$ levels in $\mathrm{HCC}$ cells, ${ }^{27}$ we investigated whether $\mathrm{Cu}$ depletion would alter the metabolic flexibility of HCC cells under hypoxic conditions. To address this question, SNU398 or SNU449 cells harboring stable genetic knockdown of CTR 1 were exposed to hypoxic $\left(1 \% \mathrm{O}_{2}\right)$ or normoxic $\left(21 \% \mathrm{O}_{2}\right)$ conditions and evaluated for expression of key glycolytic genes (Fig. 4a and b). As predicted, exposure to hypoxia for 48 hours significantly induced expression of the glycolytic genes PKM, GLUT1, and LDHA. However, mRNA knockdown of CTR1 significantly blocked the hypoxia-mediated increase in GLUT1 transcripts, while also reducing PKM or $L D H A$ transcripts in SNU398 or SNU449 cells, respectively. These findings that reduced CTR1 expression decreases the hypoxia-dependent transcription of several glycolytic genes suggest that this response is partly $\mathrm{Cu}$-dependent. In parallel to monitoring glycolytic gene expression upon hypoxic exposure, we investigated whether hypoxia would alter $\mathrm{Cu}$ transporter expression in a similar fashion to that previously observed in human pulmonary arterial smooth muscle cells, ${ }^{60}$ murine macrophages, ${ }^{61}$ or rodent intestinal epithelial cells. ${ }^{62}$ Similar to previous work, hypoxia exposure significantly elevated transcription of $A T P 7 A$, but only illustrated modest changes in $S L C 31 A 1, S L C 31 A 2$, and $A T P 7 B$ across both cell lines (Fig. 4a and b). Notably, this response was further enhanced in the presence of reduced CTR1 upon hypoxic exposure. Following the trends in the transcriptional data, glucose consumption and lactate production increased upon exposure to hypoxia but significantly decreased upon stable knockdown of CTR1 in SNU398 and SNU449 cells (Fig. 4c and d). To examine the functional consequences of a Cu-dependent alteration in metabolic rewiring, we assessed whether SNU398 or SNU449 cells deficient in CTR1 could survive in a hypoxic environment (Fig. 4e and f). While CTR1 knockdown alone was sufficient to significantly reduce clonogenic survival, this effect was further accentuated under hypoxic conditions after seven days.
Taken as a whole, a sustained reduction in CTR1 is sufficient to alter the glycolytic metabolism required to propel the tumorigenic properties of HCC cells undergoing hypoxic stress.

\section{Hypoxia in combination with TTM treatment curtailed HCC metabolism}

To determine whether $\mathrm{Cu}$ chelation would alter metabolic flexibility in HCC, SNU 398 and SNU449 cells treated with TTM were exposed to hypoxic or normoxic conditions and expression of key glycolytic genes was evaluated (Fig. 5a and b). As expected, exposure to hypoxia induced the robust and significant transcription of PKM, GLUT1, and LDHA genes (Fig. 5a and b). However, treatment with TTM revealed a significant Cu-dependent reduction in PKM, GLUT1, and $L D H A$ when compared to hypoxia treatment alone in SNU398 cells, while trending similarly in SNU449 cells (Fig. 5a and b). These results agree with a previous study from Feng and collegues ${ }^{63}$ that demonstrated that the $\mathrm{Cu}$ and $\mathrm{Zn}$ chelator tetraethylenepentamine (TEPA) could suppress HIF-1 transcriptional activity and the subsequent expression of hypoxia-responsive genes. Next, to assess whether differential oxygen tensions foster differential $\mathrm{Cu}$ uptake, we measured intracellular $\mathrm{Cu}$ levels using ICP-MS analysis from SNU398 and SNU449 cells after exposure to hypoxia $\left(1 \% \mathrm{O}_{2}\right)$ for 48 hours. Accordingly, intracellular $\mathrm{Cu}$ levels were significantly elevated upon hypoxic conditions in SNU398 cells and trended upwards in SNU449 cells (Fig. 5g). These data support the idea that hypoxia induces differential $\mathrm{Cu}$ utilization within HCC cells.

Importantly, both glucose consumption and lactate production aligned with the transcriptional findings, as these measurements significantly diminished upon the TTM-hypoxia combination compared to hypoxia exposure alone (Fig. $5 \mathrm{c}$ and d). Hence, these observations indicate that pharmacologic reductions in $\mathrm{Cu}$ availability hinder the reprogramming of glucose metabolism in HCC. Finally, to evaluate whether targeting intracellular $\mathrm{Cu}$ levels within a hypoxic environment will change HCC tumorigenic properties, we assessed the ability for TTM-treated SNU398 and SNU449 cells to survive under hypoxia upon seeding at low density. TTM treatment alone significantly blunted clonogenic growth in a dose-dependent manner and when combined with hypoxic conditions (Fig. 5e and f). Taken together, these results support the notion that limiting $\mathrm{Cu}$ availability within a uniform hypoxic microenvironment works to restrict both glucose metabolism and survival ability of HCC cells.

\section{Discussion}

In the present study, we highlighted $\mathrm{Cu}$ homeostasis as a targetable vulnerability within HCC and provided early evidence to suggest $\mathrm{Cu}$ chelation as a supplemental treatment option for patients with this disease. The mining of publicly available, cancer genomic data sets uncovered several features that may explain the consistent clinical findings of elevated $\mathrm{Cu}$ levels across HCC patients. We demonstrated that dysregulation of $\mathrm{Cu}$ homeostasis, through altered expression of $\mathrm{Cu}$ transporter genes, correlated with unfavorable outcomes in HCC patients. In support of this data, $\mathrm{Cu}$ transporter 


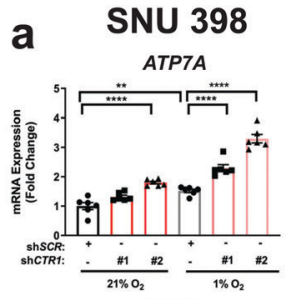

ATP7B

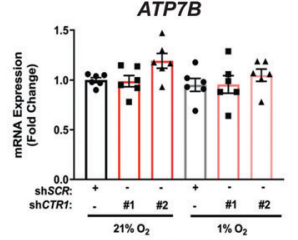

SLC31A1

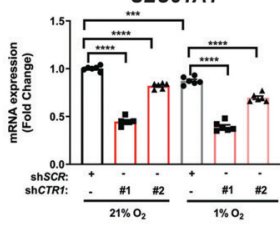

SLC31A2

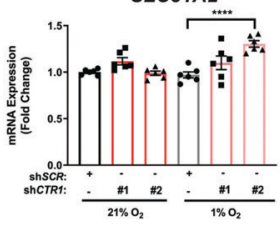

GLUT1
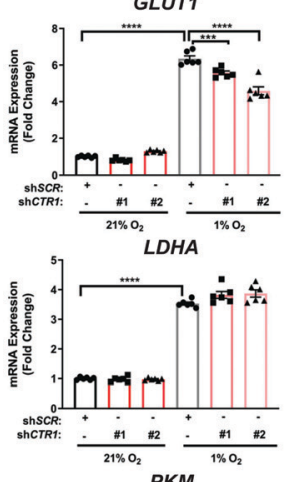

PKM

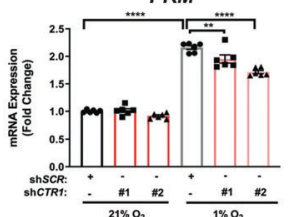

b SNU 449

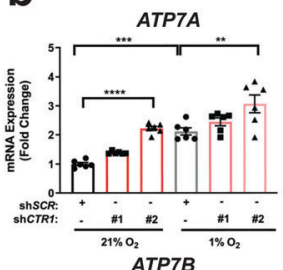

ATP7B

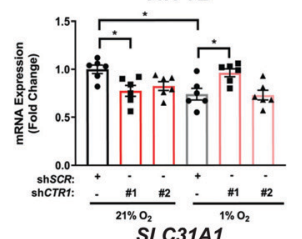

${ }^{21 \% \mathrm{O}_{2}}$ SLC31A

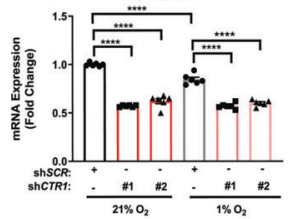

SLC31A2

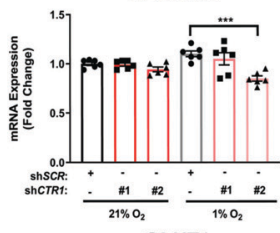

GLUT1
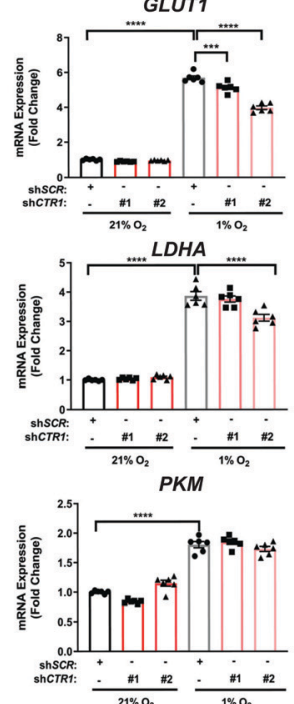

C

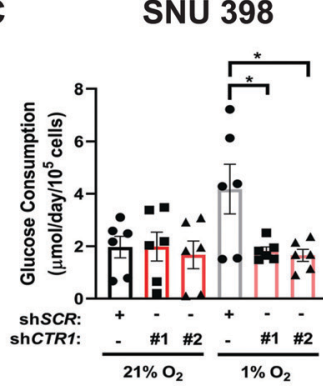

d

SNU 449

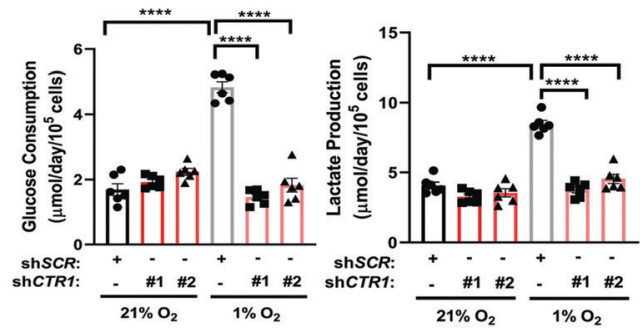

e

SNU 398
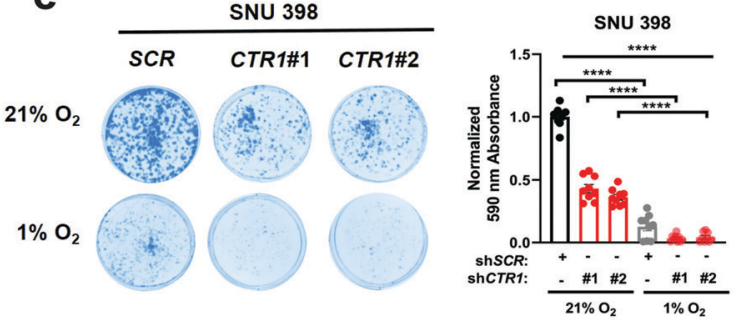

f
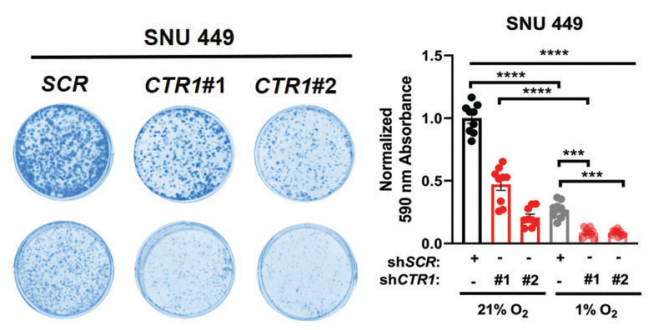

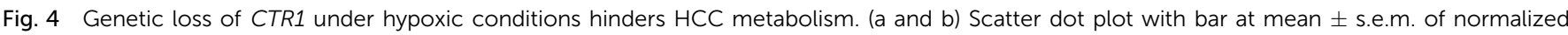

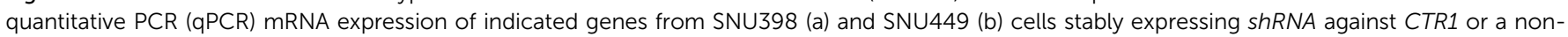

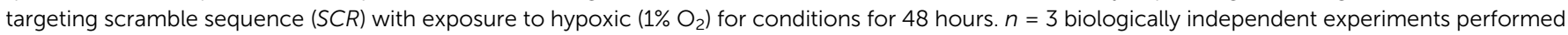

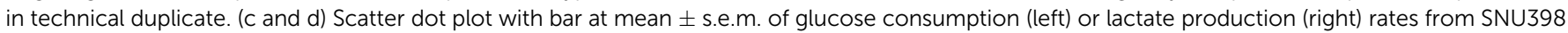

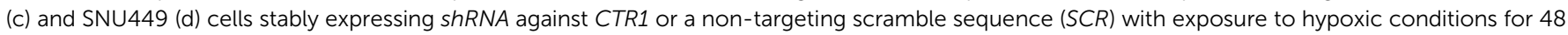

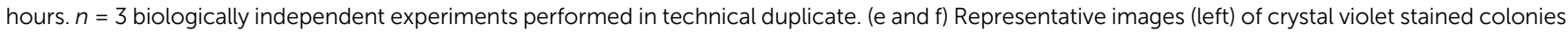

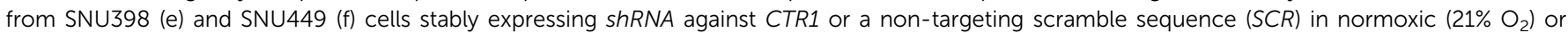

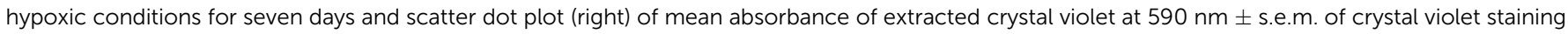

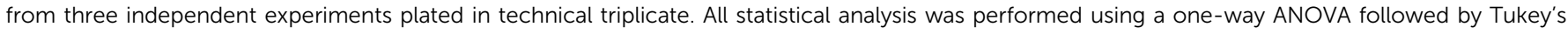
multiple comparison test. ${ }^{\star} P<0.0332,{ }^{\star *} P<0.0021,{ }^{\star} * \star P<0.0002,{ }^{\star}{ }^{* \star \star} P<0.0001$.

expression in a panel of human liver cell lines reflected these observations. While the SLC31A1 (CTR1) levels were decreased in both human liver tumor tissues and cell lines, which suggests HCC tumors could be $\mathrm{Cu}$ deficient, $\mathrm{Cu}$ levels were significantly elevated in rat liver tumors and several human HCC cell lines that aligned with reduced CCS protein abundance. Thus, we have demonstrated 
a

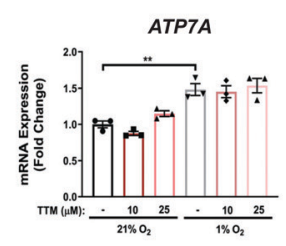

ATP7B

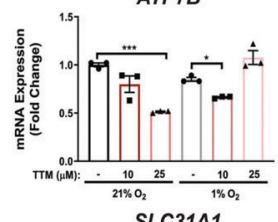

SLC31A1

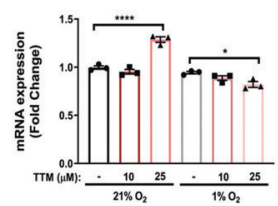

SLC31A2

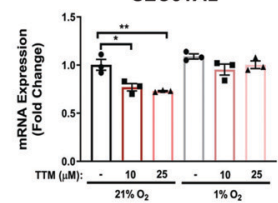

GLUT1

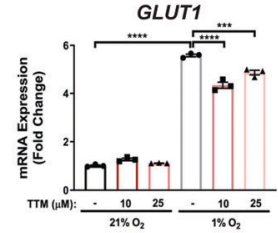

LDHA

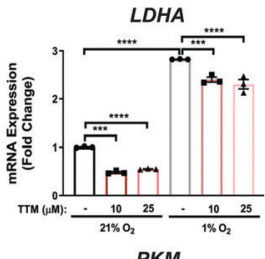

PKM

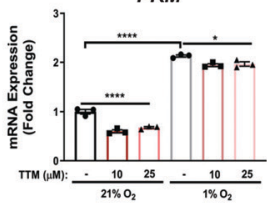

b SNU 449

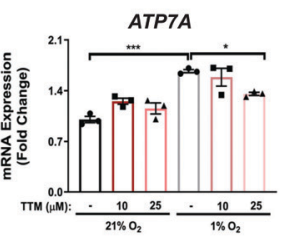

ATP7B
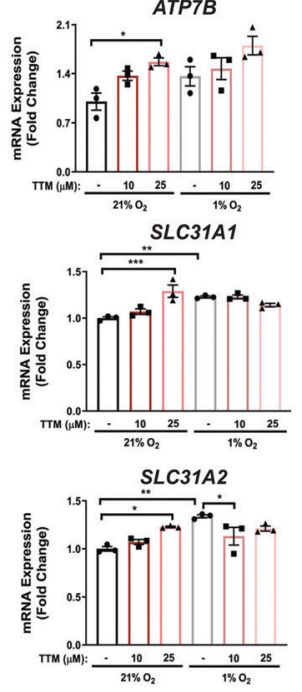

GLUT1

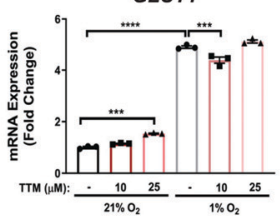

LDHA

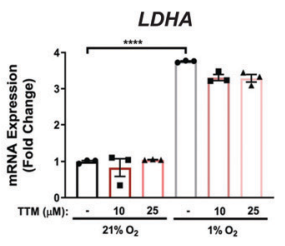

PKM

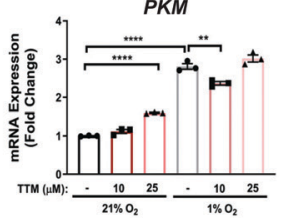

C
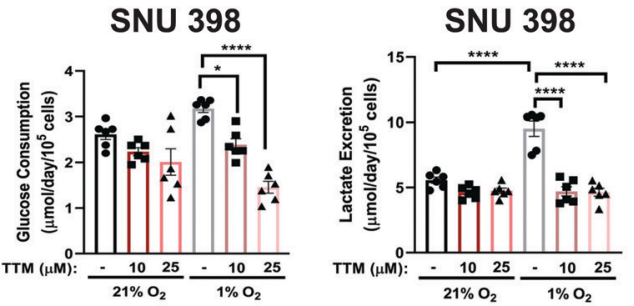

d

SNU 449
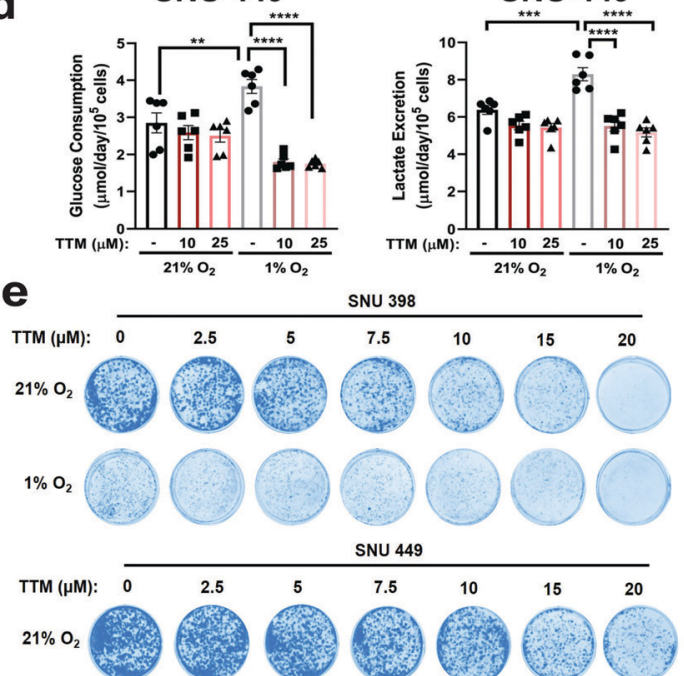

f

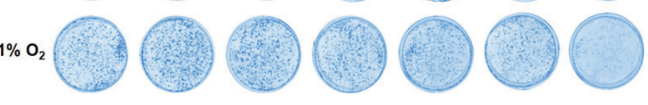

SNU 398
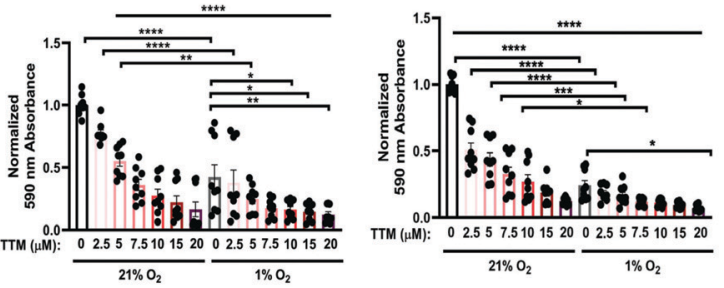

g

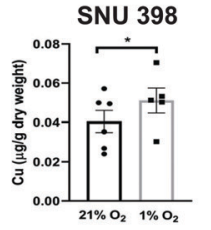

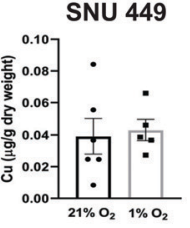

Fig. 5 Hypoxic conditions in combination with TTM alter HCC metabolism. (a and b) Scatter dot plot with bar at mean \pm s.e.m. of normalized quantitative PCR (qPCR) mRNA expression of indicated genes from SNU398 (a) and SNU449 (b) cells upon treatment with $10 \mu$ M or $25 \mu$ M TTM or exposure to hypoxic (1\% $\mathrm{O}_{2}$ ) conditions for 48 hours. Representative $n$ of three biologically independent experiments performed in technical triplicate. (c and d) Scatter dot plot with bar at mean \pm s.e.m. of glucose consumption (left) or lactate excretion (right) rates from SNU398 (c) and SNU449 (d) cells upon treatment with $10 \mu$ M or 25 $\mu \mathrm{M}$ TTM or exposure to hypoxic conditions for 48 hours. $n=3$ biologically independent experiments performed in technical duplicate. (e) Representative images of crystal violet stained colonies from SNU398 (top) and SNU449 (bottom) HCC cells treated with vehicle (DMSO) or increasing concentrations of TTM in normoxic $\left(21 \% \mathrm{O}_{2}\right)$ or hypoxic conditions for seven days of three independent experiments plated in technical triplicate. (f) Scatter dot plot of mean absorbance of extracted crystal violet at $590 \mathrm{~nm} \pm$ s.e.m. of crystal violet staining experiments in (e). (g) Scatter dot plot of ICP-MS detection with bar at mean $\mathrm{Cu}\left(\mu \mathrm{g} \mathrm{g}^{-1}\right.$ dry weight) from indicated HCC cell lines exposed to normoxic or hypoxic conditions. $n=6$ biologically independent experiments performed and statistical analysis was performed with a paired, two-tailed student $t$-test $* P=0.0257$. For panels a-f, statistical analysis was performed using a one-way ANOVA followed by Tukey's multiple comparison test. ${ }^{*} P<0.0332,{ }^{* *} P<0.0021,{ }^{* * *} P<0.0002,{ }^{* * * * P}<0.0001$.

utilizing both molecular and genetic approaches that $\mathrm{Cu}$ levels are indeed elevated in the context of liver cancer and this marked increase is associated with reduced mRNA expression of SLC31A1,
$S L C 31 A 2$, and $A T P 7 B$, suggesting that increased $\mathrm{Cu}$ content of HCC tumors may be driven by the loss of $A T P 7 B$ instead of the downregulation of SLC31A1 (CTR1) and SLC31A2 (CTR2). 
Alternatively, cancer cell lines increase nutrient scavenging in the form of macropinocytosis, ${ }^{64}$ which was recently proven to be a mechanism for cancer cells to acquire $\mathrm{Cu}$ and could be responsible for the increased $\mathrm{Cu}$ levels in $\mathrm{HCC}$ cell lines and tumor tissue. However, future studies must be conducted to further investigate this concept. To the best of our knowledge, this study is the first to identify a relationship between the expression of $\mathrm{Cu}$ transporter genes and prognosis in HCC patients. These results support previous studies that described $\mathrm{Cu}$ levels as significantly higher in both patient serum ${ }^{22-25}$ and resected tumors. ${ }^{26-28}$ Considering the trend of poorer diseasefree survival for HCC patients with altered $\mathrm{Cu}$ transporter copy number (Fig. 1d), and a previous report where small tumors $(<35 \mathrm{~mm})$ yielded high $\mathrm{Cu}$ levels that correlated positively with differentiation status of the tumor, ${ }^{27}$ it is likely that $\mathrm{Cu}$ homeostasis contributes more to hepatocarcinogenesis than to HCC progression. Even though our findings reveal dysfunctional $\mathrm{Cu}$ transport and provide essential insights toward the development of alternative therapeutics in the treatment of HCC, further molecular studies are needed define the role of cuproproteins in the pathogenesis of HCC.

In addition, we demonstrated that CTR1 is necessary for cellular proliferation, clonogenic survival, and anchorageindependent growth of HCC cell lines. These results complement experiments performed by Porcu et al., where transient knockdown of CTR1 reduced cell viability, cell cycle progression, and cell migration in human immortalized hepatic progenitor or hepatoma cells, while treatment with $\mathrm{CuSO}_{4}$ slightly enhanced these properties. ${ }^{24}$ Although the authors suggested that MYC is responsive to $\mathrm{Cu}$ levels, whether other transcriptional regulators mediate these $\mathrm{Cu}$-dependent responses remains to be determined. However, elementary proof may lie in the correspondence between MYC target genes and microarray data that revealed an upregulation in genes associated with cell growth, cell migration, angiogenesis, and small GTPase mediated signal transduction upon exposure to high concentrations of $\mathrm{CuSO}_{4}$ in HepG2 cells. ${ }^{65}$ Taken together, protein factors that regulate the above processes, such as the frequently mutated TERT, $\beta$-Catenin, or p16, may influence $\mathrm{Cu}$-dependent responses and represent important targets for future studies. Furthermore, we demonstrated that hypoxia in combination with CTR1 deficiency attenuated HCC glycolytic metabolism and tumorigenic properties. Importantly, the liver is one of few organs that maintains an oxygen gradient, however, liver cancers seem to nurture a remarkedly hypoxic environment. ${ }^{66,67}$ Hypoxia is a known driver of oncogenesis and regulates processes including epithelial-to-mesenchymal transition, ${ }^{68}$ angiogenesis, ${ }^{69}$ and invasion. ${ }^{70}$ Considered in conjunction, manipulating $\mathrm{Cu}$ availability may therefore represent a useful approach for modulating one or more of these hypoxicdependent responses which shape tumorigenesis in HCC.

In parallel, we demonstrated that treatment with the $\mathrm{Cu}$ specific chelator TTM inhibits HCC tumorigenic properties. Although animal studies in HCC have not yet been performed using TTM, an early study of HCC tumor xenografts showed that $\mathrm{Cu}$ chelation with trientine, another $\mathrm{Cu}$ chelator, can induce apoptosis and reduce tumor volume. ${ }^{71}$ Despite this preclinical study that explored $\mathrm{Cu}$ chelation as a treatment option for $\mathrm{HCC},{ }^{71}$ the efficacy of $\mathrm{Cu}$ chelation in combination with the standard-of-care therapies, TAE and TACE, has yet to be investigated. Here we provide evidence that TTM reduces the hypoxia-induced expression of glycolytic genes, which in turn, reduces both glucose utilization and lactate excretion. Based on previous work, several molecular phenomena may further support the contribution of our findings. Firstly, HCC cells exhibit "metabolic flexibility", where glucose metabolism is reprogrammed in response to increased demand for biological building blocks required of rapidly proliferating cells or stress associated with the nutrient deprivation induced by TAE or TACE. ${ }^{11}$ Key elements of liver rewiring include upregulation of GLUT1, LDHA, and PKM, which drive flux through glycolysis and towards lactate production. ${ }^{56}$ Additionally, the consistent upregulation of $A T P 7 A$ upon hypoxia suggests that liver rewiring may even extend to the reprogramming of trace metal metabolism. Moreover, metabolic flexibility can influence the angiogenic properties of tumors under hypoxia. ${ }^{72}$ In linking angiogenesis to metabolism, Végran and colleagues provided evidence to assert that lactate is sufficient to promote tumor angiogenesis through the lactate/NF-kB/IL-8 axis. ${ }^{73}$ In accordance with these studies, our data suggest that TTM may reduce tumorigenic properties in the context of hypoxia by significantly blocking glucose consumption and lactate production, which constrains vascularization. Secondly, findings from Martin et al. and Feng et al. demonstrate that $\mathrm{Cu}$ contributes to the regulation of HIF-1 $\alpha$. Specifically, excessive $\mathrm{Cu}$ in the presence of hypoxia resulted in a Cu-dependent enhancement of both HRE-reporter activity and mRNA expression of hypoxia-responsive genes, while $\mathrm{Cu}$ chelation with TEPA suppressed these outputs by blocking HIF-1 $\alpha$-mediated interactions. ${ }^{63,74}$ Thus, another explanation may be that $\mathrm{Cu}$ merely functions to inhibit the upstream negative regulators of HIF- $1 \alpha$, perhaps by competing with iron for binding to prolyl-4-hydroxylases (PHD) enzymes. Finally, while the concentration of TTM required to reduce the tumorigenic properties of HCC cell lines was in the micromolar range, $\mathrm{Cu}$ chelation could improve outcomes with locoregional therapies like TACE in which chemotherapy and embolic are applied directly to the tumor vasculature. In conclusion, this work provides genetic evidence of disrupted $\mathrm{Cu}$ homeostasis in the context of HCC. Moreover, we have provided a foundation for further exploration of TTM treatment in HCC. Specifically, future studies will focus on the combination of TTM with standard-of-care locoregional therapy, as this pairing may prove a suitable strategy to combat the recurrence observed in a majority of HCC patients.

\section{Conflicts of interest}

D. C. B. holds ownership in Merlon Inc. D. C. B. is an inventor on the patent application 20150017261 entitled "Methods of treating and preventing cancer by disrupting the binding of copper in the MAP kinase pathway". No potential conflicts of interest were disclosed by the other authors. 


\section{Acknowledgements}

We thank O. Antipova for support and assistance with X-Ray Fluorescence Microscopy data collection and analysis at the Advanced Photon Source part of the Argonne National laboratory supported by the Department of Energy, Office of Basic Energy Sciences, under contract no. DE-AC02-06CH11357, A. Mancuso for materials, reagents, technical assistance, and discussions supporting this manuscript, and D. Sneddon for administrative support. This research was supported by W. W. Smith Charitable Trust \#C1604 (D. C. B.), the Pilot \& Feasibility Program Award (D. C. B) from National Institutes of Health (NIH) grant P30DK050306-21S1 for the University of Pennsylvania Center for Molecular Studies in Digestive and Liver Diseases, and Oregon Health and Science University Foundation (M. R.). R. M. Kiefer was supported by Howard Hughes Medical Insitute (HHMI) Medical Research Fellows Program.

\section{References}

1 R. L. Siegel, K. D. Miller and A. Jemal, CA-Cancer J. Clin., 2019, 7-34.

2 S. F. Altekruse, S. J. Henley, J. E. Cucinelli and K. A. McGlynn, Am. J. Gastroenterol., 2014, 109, 542-553.

3 H. B. El-Serag, N. Engl. J. Med., 2011, 365, 1118-1127.

4 K. Schulze, S. Imbeaud, E. Letouzé, L. B. Alexandrov, J. Calderaro, S. Rebouissou, G. Couchy, C. Meiller, J. Shinde, F. Soysouvanh, A.-L. Calatayud, R. Pinyol, L. Pelletier, C. Balabaud, A. Laurent, J.-F. Blanc, V. Mazzaferro, F. Calvo, A. Villanueva, J-C. Nault, P. Bioulac-Sage, M. R. Stratton, J. M. Llovet and J. Zucman-Rossi, Nat. Genet., 2015, 47, 505-511. 5 J. Bruix and M. Sherman, Hepatology, 2011, 53, 1020-1022.

6 E. Terzi, F. Piscaglia, L. Forlani, C. Mosconi, M. Renzulli, L. Bolondi and R. Golfieri, BMC Cancer, 2014, 14, 601.

7 J. M. Llovet, S. Ricci, V. Mazzaferro, P. Hilgard, E. Gane, J.-F. Blanc, A. C. de Oliveira, A. Santoro, J.-L. Raoul, A. Forner, M. Schwartz, C. Porta, S. Zeuzem, L. Bolondi, T. F. Greten, P. R. Galle, J.-F. Seitz, I. Borbath, D. Häussinger, T. Giannaris, M. Shan, M. Moscovici, D. Voliotis and J. Bruix, N. Engl. J. Med., 2008, 359, 378-390.

8 H. K. Sanoff, Y. Chang, J. L. Lund, B. H. O'Neil and S. B. Dusetzina, Oncologist, 2016, 21, 1113-1120.

9 S. B. Paul, S. Gamanagatti, V. Sreenivas, S. H. Chandrashekhara, A. Mukund, M. S. Gulati, A. K. Gupta and S. K. Acharya, Indian J. Radiol. Imaging, 2011, 21, 113-120.

10 T. P. F. Gade, E. Tucker, M. S. Nakazawa, S. J. Hunt, W. Wong, B. Krock, C. N. Weber, G. J. Nadolski, T. W. I. Clark, M. C. Soulen, E. E. Furth, J. D. Winkler, R. K. Amaravadi and M. C. Simon, Radiology, 2017, 000, 160728.

11 N. Perkons, R. Kiefer, M. Noji, M. Pourfathi, D. Ackerman, S. Siddiqui, D. Tischfield, E. Profka, O. Johnson, S. Pickup, A. Mancuso, A. Pantel, G. Denburg, M. R. Nadolski, S. Hunt, E. Furth, S. Kadlecek and T. Gade, Hepatology, 2019, Epub.

12 W. Xu, J. H. Kwon, Y. H. Moon, Y. B. Kim, Y. S. Yu, N. Lee, K. Y. Choi, Y. S. Kim, Y. K. Park, B. W. Kim and H. J. Wang, J. Cancer Res. Clin. Oncol., 2014, 140, 1507-1515.
13 P. C. Bull, G. R. Thomas, J. M. Rommens, J. R. Forbes and D. W. Cox, Nat. Genet., 1993, 5, 327-337.

14 R. E. Tanzi, K. Petrukhin, I. Chernov, J. L. Pellequer, W. Wasco, B. Ross, D. M. Romano, E. Parano, L. Pavone and L. M. Brzustowicz, Nat. Genet., 1993, 5, 344-350.

15 T. Kumagi, N. Horiike, K. Michitaka, A. Hasebe, K. Kawai, Y. Tokumoto, S. Nakanishi, S. Furukawa, Y. Hiasa, H. Matsui, K. Kurose, B. Matsuura and M. Onji, J. Gastroenterol., 2004, 39, 1165-1169.

16 T. Kumagi, N. Horiike, M. Abe, K. Kurose, H. Iuchi, T. Masumoto, K. Joko, S. M. F. Akbar, K. Michitaka and M. Onji, Intern. Med., 2005, 44, 439-443.

17 H. Iwadate, H. Ohira, T. Suzuki, K. Abe, J. Yokokawa, J. Takiguchi, T. Rai, H. Orikasa, A. Irisawa, K. Obara, R. Kasukawa and Y. Sato, Intern. Med., 2004, 43, 1042-1045.

18 R. Thattil and J. F. Dufour, World J. Gastroenterol., 2013, 19, 2110-2113.

19 J. Pfeiffenberger, C. Mogler, D. N. Gotthardt, H. SchulzeBergkamen, T. Litwin, U. Reuner, H. Hefter, D. Huster, P. Schemmer, A. Członkowska, P. Schirmacher, W. Stremmel, D. Cassiman and K. H. Weiss, Liver Int., 2015, 35, 1615-1622.

20 D. Huster, T. D. Purnat, J. L. Burkhead, M. Ralle, O. Fiehn, F. Stuckert, N. E. Olson, D. Teupser and S. Lutsenko, J. Biol. Chem., 2007, 282, 8343-8355.

21 D. Huster, Ann. N. Y. Acad. Sci., 2014, 1315, 37-44.

22 J. L. Poo, R. Rosas-Romero, A. C. Montemayor, F. Isoard and M. Uribe, J. Gastroenterol., 2003, 38, 45-51.

23 O. A. El Fotouh, H. A. El Aziz, M. Galal and N. El Nakeeb, Egypt. Liver J., 2012, 2, 7-11.

24 C. Porcu, L. Antonucci, B. Barbaro, B. Illi, S. Nasi, M. Martini, A. Licata, L. Miele, A. Grieco and C. Balsano, Oncotarget, 2018, 9, 9325-9343.

25 A. M. Attia, S. M. Attalla, E. A. M. E. Barakat, M. E. S. Zaki and N. Y. Elkhouly, Indian J. Forensic Med. Toxicol., 2019, 13, 398-404.

26 M. Ebara, H. Fukuda, R. Hatano, H. Saisho, Y. Nagato, K. Suzuki, K. Nakajima, M. Yukawa, F. Kondo, A. Nakayama and H. Sakurai, J. Hepatol., 2000, 33, 415-422.

27 M. Ebara, H. Fukuda, R. Hatano, M. Yoshikawa, N. Sugiura, H. Saisho, F. Kondo and M. Yukawa, Oncology, 2003, 65, 323-330.

28 J. Jie, S. Hao, Y. Hongxiu, Y. Huiying, M. Jun, W. Chenji, Y. Mingjie and M. Yong, J. Trace Elem. Med. Biol., 2007, 21, 255-260.

29 J. Lee, J. R. Prohaska and D. J. Thiele, Proc. Natl. Acad. Sci. U. S. A., 2001, 98, 6842-6847.

30 Y. M. Kuo, B. Zhou, D. Cosco and J. Gitschier, Proc. Natl. Acad. Sci. U. S. A., 2001, 98, 6836-6841.

31 P. V. E. Van Den Berghe, D. E. Folmer, H. E. M. Malingré, E. Van Beurden, A. E. M. Klomp, B. Van De Sluis, M. Merkx, R. Berger and L. W. J. Klomp, Biochem. J., 2007, 407, 49-59.

32 J. Bertinato, E. Swist, L. J. Plouffe, S. P. J. Brooks and M. R. L'Abbé, Biochem. J., 2008, 409, 731-740.

33 L. Nyasae, R. Bustos, L. Braiterman, B. Eipper and A. Hubbard, Am. J. Physiol.: Gastrointest. Liver Physiol, 2007, 292, G1181-G1194.

34 L. Pase, I. Voskoboinik, M. Greenough and J. Camakaris, Biochem. J., 2004, 378, 1031-1037. 
35 L. Krishnamoorthy, J. A. Cotruvo, J. Chan, H. Kaluarachchi, A. Muchenditsi, V. S. Pendyala, S. Jia, A. T. Aron, C. M. Ackerman, M. N. V. Wal, T. Guan, L. P. Smaga, S. L. Farhi, E. J. New, S. Lutsenko and C. J. Chang, Nat. Chem. Biol., 2016, 12, 586-592.

36 M. L. Turski and D. J. Thiele, J. Biol. Chem., 2009, 284, 717-721.

37 D. C. Brady, M. S. Crowe, M. L. Turski, G. A. Hobbs, X. Yao, A. Chaikuad, S. Knapp, K. Xiao, S. L. Campbell, D. J. Thiele and C. M. Counter, Nature, 2014, 509, 492-496.

38 T. Tsang, J. M. Posimo, A. A. Gudiel, M. Cicchini, D. M. Feldser and D. C. Brady, Nat. Cell Biol., 2020, 22, 412-424.

39 G. J. Brewer, R. D. Dick, D. K. Grover, V. LeClaire, M. Tseng, M. Wicha, K. Pienta, B. G. Redman, T. Jahan, V. K. Sondak, M. Strawderman, G. LeCarpentier and S. D. Merajver, Clin. Cancer Res., 2000, 6, 1-10.

40 Q. Pan, C. G. Kleer, K. L. Van Golen, J. Irani, K. M. Bottema, C. Bias, M. De Carvalho, E. A. Mesri, D. M. Robins, R. D. Dick, G. J. Brewer and S. D. Merajver, Cancer Res., 2002, 62, 4854-4859.

41 N. Chan, A. Willis, N. Kornhauser, M. Mward, S. B. Lee, E. Nackos, B. R. Seo, E. Chuang, T. Cigler, A. Moore, D. Donovan, M. V. Cobham, V. Fitzpatrick, S. Schneider, A. Wiener, J. Guillaume-Abraham, E. Aljom, R. Zelkowitz, J. D. Warren, M. E. Lane, C. Fischbach, V. Mittal and L. Vahdat, Clin. Cancer Res., 2017, 23, 666-676.

42 R. M. Kiefer, S. J. Hunt, S. Pulido, S. Pickup, E. E. Furth, M. C. Soulen, G. J. Nadolski and T. P. Gade, J. Vasc. Interv. Radiol, 2017, 28, 1043-1050.e2.

43 S. Vogt, J. Maser and C. Jacobsen, J. Phys. IV, 2003, 617-622. 44 T. D. Schmittgen and K. J. Livak, Nat. Protoc., 2008, 3, 1101-1108. 45 M. Jain, R. Nilsson, S. Sharma, N. Madhusudhan, T. Kitami, A. L. Souza, R. Kafri, M. W. Kirschner, C. B. Clish and V. K. Mootha, Science, 2012, 336, 1040-1044.

46 G. F. Brady, S. Galbán, X. Liu, V. Basrur, J. D. Gitlin, K. S. J. Elenitoba-Johnson, T. E. Wilson and C. S. Duckett, Mol. Cell. Biol., 2010, 30, 1923-1936.

47 A. Zimmermann, Tumors and Tumor-Like Lesions of the Hepatobiliary Tract, Springer International Publishing, 2016, pp. 1-29.

48 C. Cox, T. N. Teknos, M. Barrios, G. J. Brewer, R. D. Dick and S. D. Merajver, Laryngoscope, 2001, 111, 696-701.

49 D. C. Brady, M. S. Crowe, D. N. Greenberg and C. M. Counter, Cancer Res., 2017, 77, 6240-6252.

50 D. C. Brady, M. S. Crowe, M. L. Turski, G. A. Hobbs, X. Yao, A. Chaikuad, S. Knapp, K. Xiao, S. L. Campbell, D. J. Thiele and C. M. Counter, Nature, 2014, 509, 492-496.

51 S. Ishida, P. Andreux, C. Poitry-Yamate, J. Auwerx and D. Hanahan, Proc. Natl. Acad. Sci. U. S. A. 2013, 110, 19507-19512.

52 D. Fodor, I. Jung, S. Turdean, C. Satala and S. Gurzu, World J. Hepatol., 2019, 11, 294-304.

53 H. Wu, L. Pan, C. Gao, H. Xu, Y. Li, L. Zhang, L. Ma, L. Meng, X. Sun and H. Qin, Molecules, 2019, 24, 1993.

54 T. Amann, U. Maegdefrau, A. Hartmann, A. Agaimy, J. Marienhagen, T. S. Weiss, O. Stoeltzing, C. Warnecke, J. Schölmerich, P. J. Oefner, M. Kreutz, A. K. Bosserhoff and C. Hellerbrand, Am. J. Pathol., 2009, 174, 1544-1552.
55 H. R. Jung, H. M. Kang, J. W. Ryu, D. S. Kim, K. H. Noh, E. S. Kim, H. J. Lee, K. S. Chung, H. S. Cho, N. S. Kim, D. S. Im, J. H. Lim and C. R. Jung, Sci. Rep., 2017, 7, 1-14. 56 N. Hay, Nat. Rev. Cancer, 2016, 16, 635-649.

57 Y. B. A. Kang, J. Eo, S. Mert, M. L. Yarmush and O. B. Usta, Sci. Rep., 2018, 8, 1-13.

58 C. C. L. Wong, A. K. L. Kai and I. O. L. Ng, Front. Med., 2014, 8, 33-41.

59 D. K.-C. Chiu, A. P.-W. Tse, C. T. Law, I. M.-J. Xu, D. Lee, M. Chen, R. K.-H. Lai, V. W.-H. Yuen, J. W.-S. Cheu, D. W.-H. Ho, C. M. Wong, H. Zhang, I. O.-L. Ng and C. C.-L. Wong, Cell Death Dis., 2019, 10, 1-16.

60 A. M. Zimnicka, H. Tang, Q. Guo, F. K. Kuhr, M.-J. Oh, J. Wan, J. Chen, K. A. Smith, D. R. Fraidenburg, M. S. R. Choudhury, I. Levitan, R. F. Machado, J. H. Kaplan and J. X. J. Yuan, PLoS One, 2014, 9, e90544.

61 C. White, T. Kambe, Y. G. Fulcher, S. W. Sachdev, A. I. Bush, K. Fritsche, J. Lee, T. P. Quinn and M. J. Petris, J. Cell Sci., 2009, 122, 1315-1321.

62 L. Xie and J. F. Collins, Am. J. Physiol.: Cell Physiol., 2011, 300, C1298-C1305.

63 W. Feng, F. Ye, W. Xue, Z. Zhou and Y. J. Kang, Mol. Pharmacol., 2009, 75, 174-182.

64 L. Aubert, N. Nandagopal, Z. Steinhart, G. Lavoie, S. Nourreddine, J. Berman, M. K. Saba-El-Leil, D. Papadopoli, S. Lin, T. Hart, G. Macleod, I. Topisirovic, L. Gaboury, C. J. Fahrni, D. Schramek, S. Meloche, S. Angers and P. P. Roux, Nat. Commun., 2020, 11, 1-15.

65 O. S. Min, J. Li and J. H. Freedman, Physiol. Genomics, 2009, 38, 386-401.

66 A. J. Brooks, J. Eastwood, I. J. Beckingham and K. J. Girling, Br. J. Anaesth., 2004, 92, 735-737.

67 T. S. Leary, J. R. Klinck, G. Hayman, P. Friend, N. V. Jamieson and A. K. Gupta, Anaesthesia, 2002, 57, 1128-1133.

68 D. F. Higgins, K. Kimura, W. M. Bernhardt, N. Shrimanker, Y. Akai, B. Hohenstein, Y. Saito, R. S. Johnson, M. Kretzler, C. D. Cohen, K. U. Eckardt, M. Iwano and V. H. Haase, J. Clin. Invest., 2007, 117, 3810-3820.

69 R. Du, K. V. Lu, C. Petritsch, P. Liu, R. Ganss, E. Passegué, H. Song, S. VandenBerg, R. S. Johnson, Z. Werb and G. Bergers, Cancer Cell, 2008, 13, 206-220.

70 B. Krishnamachary, S. Berg-Dixon, B. Kelly, F. Agani, D. Feldser, G. Ferreira, N. Iyer, J. LaRusch, B. Pak, P. Taghavi and G. L. Semenza, Cancer Res., 2003, 63, 1138-1143.

71 J. Yoshii, H. Yoshiji, S. Kuriyama, Y. Ikenaka, R. Noguchi, H. Okuda, H. Tsujinoue, T. Nakatani, H. Kishida, D. Nakae, D. E. Gomez, M. S. De Lorenzo, A. M. Tejera and H. Fukui, Int. J. Cancer, 2001, 94, 768-773.

72 P. Sonveaux, T. Copetti, C. J. De Saedeleer, F. Végran, J. Verrax, K. M. Kennedy, E. J. Moon, S. Dhup, P. Danhier, F. Frérart, B. Gallez, A. Ribeiro, C. Michiels, M. W. Dewhirst and O. Feron, PLoS One, 2012, 7, e33418.

73 F. Végran, R. Boidot, C. Michiels, P. Sonveaux and O. Feron, Cancer Res., 2011, 71, 2550-2560.

74 F. Martin, T. Linden, D. M. Katschinski, F. Oehme, I. Flamme, C. K. Mukhopadhyay, K. Eckhardt, J. Tröger, S. Barth, G. Camenisch and R. H. Wenger, Blood, 2005, 105, 4613-4619. 